\title{
Nutrigenomic effects of glucosinolates on liver, muscle and distal kidney in parasite- free and salmon louse infected Atlantic salmon
}

Stanko Skugor ${ }^{1 *}$, Helle Jodaa Holm², Anne Kari Bjelland ${ }^{3}$, Jorge Pino ${ }^{4}, \varnothing_{\text {ystein Evensen }}^{2}$, Aleksei Krasnov ${ }^{5}$ and Simon Wadsworth ${ }^{4}$

\begin{abstract}
Background: Reduction of Lepeophtheirus salmonis infection in Atlantic salmon achieved by glucosinolates (GLs) from Brassica plants was recently reported. However, wider application of functional feeds based on GLs requires better knowledge of their positive and adverse effects.

Methods: Liver, distal kidney and muscle transcriptomes of salmon exposed to the extreme dose of GLs were profiled by microarray, while qPCR analysis followed up selected hepatic and renal responses under the extreme and moderate GLs dose during the L. salmonis challenge. Transcriptional analysis were complemented with measurements of organ indices, liver steatosis and plasma profiling, including indicators of cytolysis and bilirubin. Finally, the third trial was performed to quantify the effect of lower GLs doses on growth.

Results: The extreme GLs dose caused a decrease in hepatic fat deposition and growth, in line with microarray findings, which suggested tissue remodeling and reduction of cellular proliferation in the skeletal muscle and liver. Lower GLs inclusion levels in a follow-up trial did not show negative effects on growth. Microarray analysis of the distal kidney pointed to activation of anti-fibrotic responses under the overexposure. However, analyses of ALT, CK and AST enzymes in plasma provided no evidence of increased cytolysis and organ damage. Prevalent activation of phase-2 detoxification genes that occurred in all three tissues could be considered part of beneficial effects caused by the extreme dose of GLs. In addition, transcriptomic evidence suggested GLs-mediated iron and heme withdrawal response, including increased heme degradation in muscle (upregulation of heme oxygenase-1), decrease of its synthesis in liver (downregulation of porphobilinogen deaminase) and increased iron sequestration from blood (hepatic induction of hepcidin-1 and renal induction of intracellular storage protein ferritin). This response could be advantageous for salmon upon encountering lice, which depend on the host for the provision of iron carrying heme. Most of the hepatic genes studied by qPCR showed similar expression levels in fish exposed to GLs, lice and their combination, while renal induction of leptin suggested heightened stress by the combination of extreme dose of GLs and lice. High expression of interferon $\gamma$ (cytokine considered organ-protective in mammalian kidney) was detected at the moderate GLs level. This fish also showed highest plasma bilirubin levels (degradation product of heme), and had lowest number of attached lice, further supporting hypothesis that making heme unavailable to lice could be part of an effective anti-parasitic strategy.

(Continued on next page)
\end{abstract}

\footnotetext{
* Correspondence: Stanko_Skugor@cargill.com

${ }^{1}$ Cargill Innovation Center, Sea Lice Research Centre, Oslo, Norway

Full list of author information is available at the end of the article
} 
(Continued from previous page)

Conclusions: Modulation of detoxification and iron metabolism in Atlantic salmon tissues could be beneficial prior and during lice infestations. Investigation of anti-lice functional feeds based on low and moderate GLs inclusion levels thus deserves further attention.

Keywords: Atlantic salmon, Salmo salar, Salmon louse, Lepeophtheirus salmonis, Glucosinolates, Functional feeds, Iron, Antioxidant, Detoxification

\section{Background}

Despite significant attention given to finding alternative control strategies of the ectoparasite salmon louse Lepeophtheirus salmonis, the management of infections on salmon farms still heavily relies on the use of chemical treatments [1]. Several recent studies describe the severity of the situation in detail, including incurred economic losses [2], mortalities associated with application of chemical treatments [1] and in wild salmonid populations [3-5], risk of pathogenic virus transmission [6-8], and development of resistance to available parasiticides [9-12]. As chemical treatments are becoming limited and less efficient, there is an increasing interest in the development of anti-lice functional feeds.

Protection against lice can involve modulation of inflammation at the attachment site and induction of iron regulatory mechanisms [13-16], processes that can be modulated by diet $[17,18]$. GLs constitute a heterogeneous family of sulfur-rich secondary plant metabolites occurring in cruciferous plants that are grown and consumed worldwide. Upon mechanical damage, GLs are hydrolyzed by the enzyme myrosinase into compounds that defend plants against a wide range of herbivores, including insects and aquatic invertebrates (reviewed by [19]). Ingested GLs are also hydrolyzed by the intestinal microflora [20]. Isothiocyanates (ITCs) constitute the major bioactive fraction of the hydrolysis products of GLs, with antibacterial properties in vitro [21], and antifungal effector properties in live plant cells [22].

GLs and related products are toxic to parasites in direct contact, but not much is known about the mechanisms behind the avoidance behavior of chemical irritation. The ability to perceive volatile ITCs has been well documented, especially in insects [23]. Avoidance and attractant effects with non-host and host conditioned water respectively, were shown in behavioral tests in vitro, in a related, also parasitic louse species (Caligus rogercresseyi) [24]. An in vivo follow-up study revealed activation of putative ionotropic receptor genes that could possibly be involved in the olfaction and avoidance of salmon fed anti-lice feeds [25].

Currently, GLs and their breakdown products are attracting attention in fish nutrition research because of their parasiticidal potential against the sea louse species that infect cultured salmonids. Fish receiving GLs-based functional feeds could additionally benefit from their detoxifying and immunomodulatory properties. Modulation of cellular redox status appears to be at the core of ITCs' bioactivity (reviewed in detail by [26]). The indirect antioxidant properties of ITCs achieved through induction of phase- 2 detox enzymes are considered responsible for their anticancerogenic properties [27]. However, under certain conditions, ITCs can also induce the pro-oxidant phase-1 enzymes [26]. The positive effects on human health of GLs and ITCs present in diets rich in cruciferous vegetables were reported by several clinical studies [28-31]. However, GLs can exert anti-nutritional and toxic effects [32-36], and their wider use in aquaculture requires better knowledge of their actions. Reduced palatability and decreased growth are among the main anti-nutritional effects of overexposure to GLs/ITCs in vertebrates, (reviewed in [37]). When large quantities are ingested, the adverse health effects include deterioration of liver, kidney and thyroid function [37].

Here we report findings from several feeding trials designed to investigate both the beneficial and adverse effects of GLs, alone and during the L. salmonis challenge, on nutritional parameters, gene expression and physiological responses in Atlantic salmon. In Trial 1, Atlantic salmon not infected with lice (NI) but with an extreme inclusion level (13\%) of the GLs-containing raw ingredient in their diet (NI-13) were compared to the control group with $0 \%$ dietary GLs (NI-C); hepatic, renal and muscle transcriptomes measured by microarrays were complemented with measurements of the growth response, liver steatosis and plasma biochemistry. Trial 2 addressed the effects of the L. salmonis infection and GLs on growth, plasma biochemistry, and gene expression of GLsresponsive candidates by qPCR in liver and distal kidney of infected (I) fish exposed to control feed with 0\% GLs (IC), medium (3.6\%) (I-3.6) and extreme level of GLs (I-13). Finally, in Trial 3, a lower range of dietary GLs $(0,0.5,1$ and $2 \%$ ) were tested against $L$. salmonis infection. Growth, hepato-somatic and intestinal-somatic indices, liver steatosis and muscle tissue composition were measured in IC, I-0.5, I-1 and I-2 study groups.

\section{Results}

\section{Fish growth}

In Trial 1, no significant reduction in growth was seen in parasite free NI-13 fish at the end of the 17-18 day 
exposure period to the extreme dose of GLs (Table 1). After a longer exposure period (47 days), significant (ANOVA: $F_{(2,177)}=24.86$; I-C vs I-3.6: $P<0.0001$; I-C vs I-13: $P<0.0001)$ growth reductions were observed in Trial 2 in I-13 and I-3.6 groups, 17 and 14\% lower in comparison to I-C, respectively (Table 2). The calculated condition factor $(\mathrm{CF})$ was found to be very similar in NI-C and NI-13 (Table 1), but significantly (ANOVA: $F_{(2,177)}=$ 11.37, I-C vs I-3.6 $P<0.0001$, I-C vs I-13 $P<0.001)$ different in Trial 2 (Table 2). The lower inclusion levels in Trial 3 of the GLs-containing raw ingredient in I-0.5, I-1 and I2 did not result in significant differences in weight and CF between the dietary groups (Table 3 ). No differences in feed consumption were found in any of the trials.

\section{Plasma profiling}

A basic panel of plasma tests was performed on parasite free fish from Trial 1 (NI-C and NI-13) and lice infected fish from Trial 2 (I-C, I-3.6 and I-13) (Fig. 1). The elevated levels of profiled enzymes in plasma are considered good indicators of cytolysis and cell leakage [38]. Alanine aminotransferase (ALT) and aspartate aminotransferase (AST) are found in liver parenchymal cells, and also in kidney, muscle and other tissues [38], while creatine kinase (CK) is an enzyme that mainly increases due to leakage from muscle cells [39, 40]. No differences were found in plasma levels of ALT, AST and CK between NI-C and NI-13. Interestingly, levels of all three profiled enzymes were lower in Trial 2 during the lice infection in comparison to values measured in lice free fish in Trial 1. The two trials are directly comparable as both took place under the same conditions and at about the same time. Cholesterol levels were also significantly ( $t$-test: $\left.t_{(56)}=2.8, P=0.007\right)$ lower in infected fish than in fish not exposed to lice. Bilirubin, which is predominantly formed by the breakdown of heme present in hemoglobin [38], showed the highest level in I-3.6 and was significantly different from the level measured in I$\mathrm{C}$ and I-13 (Kruskal-Wallis H-test: $\chi^{2}=5.99, d f=2$; I-C vs I-3.6: $P=0.02$; I-13 vs I-3.6: $P=0.05)$. Stress causes ionic imbalances in fish (see Djordjevic et al. [41] and references therein). We have previously seen an increase in sodium $\left(\mathrm{Na}^{+}\right)$ions in cortisol injected salmon during

Table 1 Mean weight \pm standard deviation (SD) and mean condition factor \pm SD in not infected fish exposed to $0 \%$ of the GLs-containing raw ingredient (NI-C) and 13\% (NI-13) in Trial 1. Data was analyzed by $t$-test

\begin{tabular}{lcc}
\hline Trial 1 & $\mathrm{Nl}-\mathrm{C}(n=18)$ & $\mathrm{Nl}-13(n=18)$ \\
\hline Weight $^{\mathrm{a}}(\mathrm{g})$ & $825.6 \pm 117.5$ & $805 \pm 139$ \\
$\mathrm{CF}^{\mathrm{b}}$ & $1.52 \pm 0.08$ & $1.56 \pm 0.08$
\end{tabular}

${ }^{a}$-test: $\mathrm{t}_{(34)}=0.49, P=0.62$

${ }^{b}$ Condition factor was calculated by the formula (weight ${ }^{*} 100 /$ length ${ }^{3}$ ) for each individual fish. $\mathrm{t}$-test: $\mathrm{t}\left({ }_{34}\right)=1.37, P=0.18$
Table 2 Mean weight \pm standard deviation (SD) and condition factor \pm SD in L. salmonis-infected fish exposed to $0 \%$ of the GLs-containing raw ingredient (I-C), 3.6\% (I-3.6) and 13\% (I-13) in Trial 2. Data were analyzed by One-way ANOVA

\begin{tabular}{lccc}
\hline Trial 2 & I-C $(n=60)$ & $1-3.6(n=60)$ & $1-13(n=60)$ \\
\hline Weight $^{\mathrm{a}}(\mathrm{g})$ & $871 \pm 127$ & $751 \pm 121^{* * * *}$ & $726 \pm 113^{* * * *}$ \\
CF $^{\mathrm{b}}$ & $1.43 \pm 0.13$ & $1.54 \pm 0.16^{* * * *}$ & $1.52 \pm 0.13^{* * *}$ \\
\hline
\end{tabular}

${ }^{* * *} P<0.001,{ }^{* * * *} P<0.0001$ : significant differences in comparisons with control

${ }^{a}$ ANOVA: $F_{(2,177)}=24.86, \mathrm{I}-\mathrm{C}$ vs $\mathrm{I}-3.6 P<0.0001, \mathrm{I}-\mathrm{C}$ vs I-13 $P<0.0001$

${ }^{\mathrm{b}}$ Condition factor was calculated by the formula (weight ${ }^{*} 100 /$ length $^{3}$ ) for each individual fish. ANOVA: $F_{(2,177)}=11.37, \mathrm{I}-\mathrm{C}$ vs $\mathrm{I}-3.6 \mathrm{P}<0.0001$, I-C vs $1-13 P<0.001$

the lice challenge [42], hence we measured $\mathrm{Na}^{+}$and potassium $\left(\mathrm{K}^{+}\right)$plasma levels and calculated their ratio $(\mathrm{Na} / \mathrm{K})$ for each group. $\mathrm{Na}^{+}$decreased in NI-13 fish while $\mathrm{K}^{+}$decreased in $\mathrm{I}-13$, in comparison to their respective controls (data not shown), while the $\mathrm{Na} / \mathrm{K}$ was found to be highest in I-13.

\section{Liver steatosis}

Liver steatosis results from the three trials are shown in Fig. 2. A lowering effect of GLs on steatosis was observed in all trials, while Trial 3 captured a smaller lowering effect of lice infection on liver steatosis.

\section{Organo-somatic indices and flesh quality}

In Trial 3, the hepato-somatic index (HSI) and intestinalsomatic index (ISI) were calculated based on measurements taken from 10 fish from each of the study groups (Fig. 3). The HSI declined as the inclusion of GLs increased, being significantly (Kruskal-Wallis H-test: $\chi^{2}=$ 7.8, $d f=3, P=0.008$ ) different between I-2 and I-C. GLs showed the opposite effect on ISI, with the significant (ANOVA: $\left.F_{(3,37)}=3.8, P=0.002\right)$ difference observed between I-C and I-0.5 fish.

Flesh quality parameters were determined by the near infrared spectroscopy (NIR) performed on Norwegian quality cut (NQC) samples (Table 4). Almost all of the significant changes in the fatty acid profile were observed between I-0.5 fish and I-C, and I-2 and I-C.

Table 3 Mean weight \pm SD and condition factor \pm SD in L. salmonis-infected fish exposed to $0 \%$ of the GLs-containing raw ingredient $(\mathrm{I}-\mathrm{C}), 0.5 \%(\mathrm{I}-0.5), 1 \%(\mathrm{I}-1)$ and $2 \%(\mathrm{I}-2)$ in Trial 3

\begin{tabular}{lcccc}
\hline Trial 3 & I-C $(n=78)$ & $1-0.5(n=76)$ & $1-1(n=72)$ & $1-2(n=73)$ \\
\hline Weight $^{\mathrm{a}}$ & $540 \pm 110$ & $554 \pm 103$ & $540 \pm 119$ & $553 \pm 103$ \\
CF $^{\mathrm{b}}$ & $1.2 \pm 0.08$ & $1.2 \pm 0.08$ & $1.2 \pm 0.07$ & $1.2 \pm 0.05$ \\
\hline
\end{tabular}

ANOVA: $F_{(3,292)}=0.4, P=0.75$

${ }^{\mathrm{b}}$ Condition factor was calculated by the formula (weight*100/length ${ }^{3}$ ) for each individual fish. ANOVA: $F_{(3,291)}=1.85, P=0.14$ 


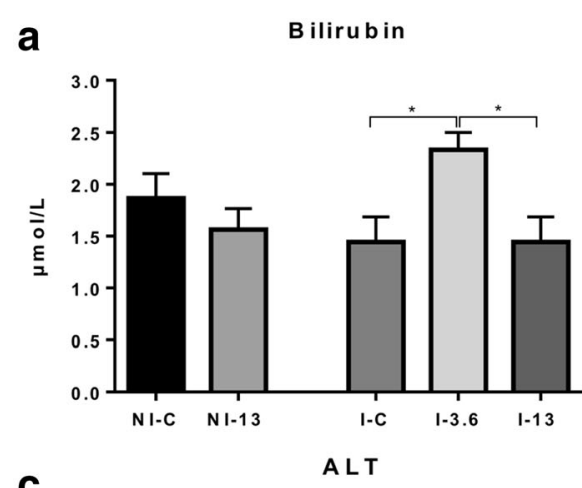

b cholesterol

C
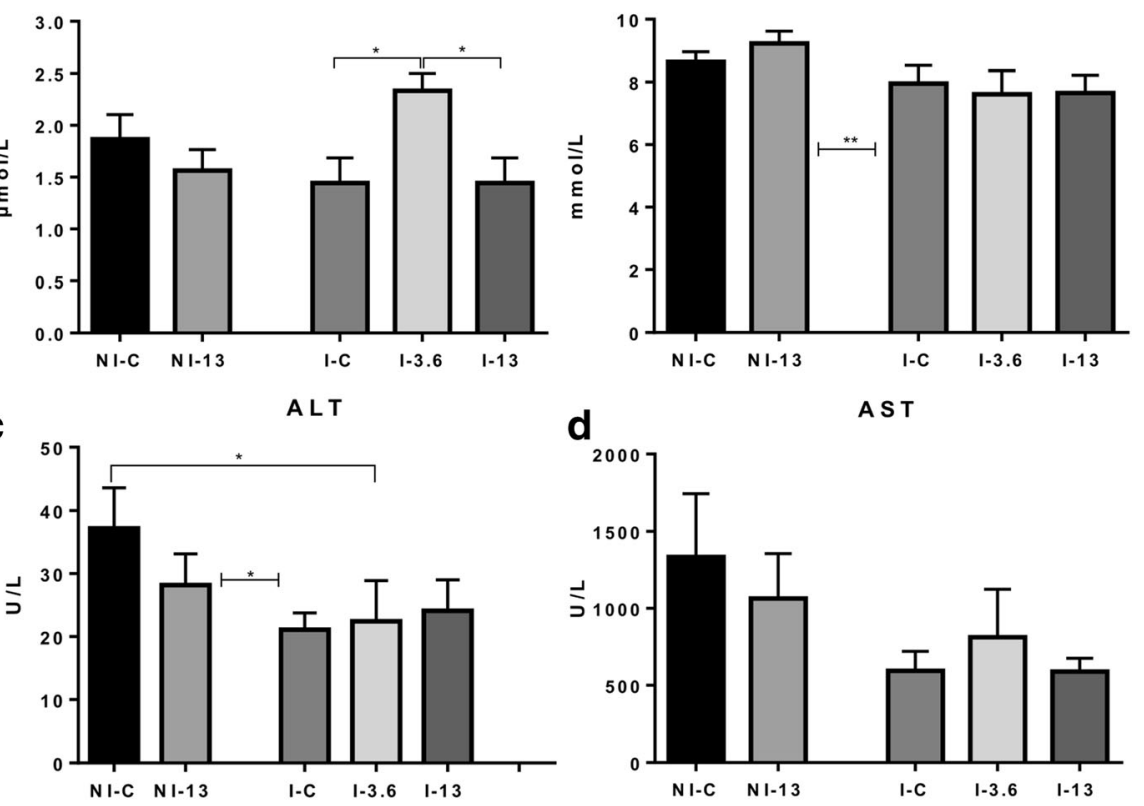

d

A S T

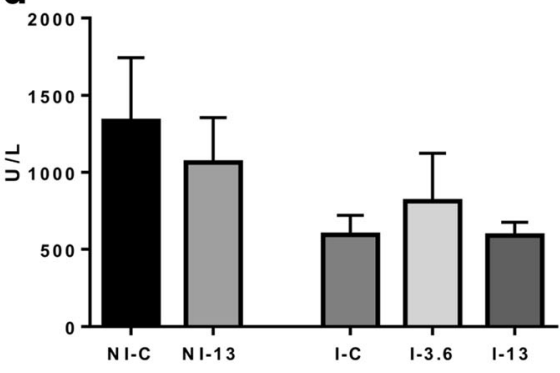

e

$\mathrm{CK}$

f

$\mathrm{Na} / \mathrm{K}$
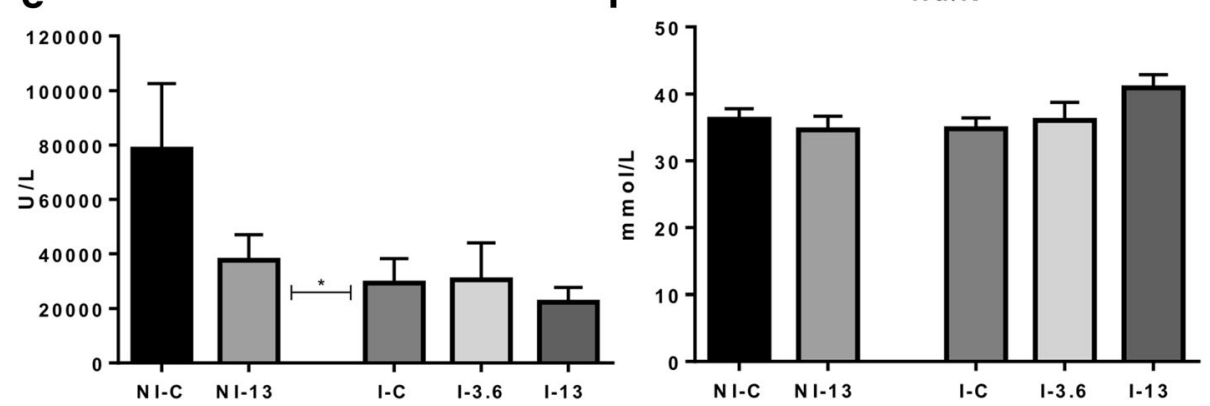

Fig. 1 Blood plasma levels (mean \pm SEM) of total bilirubin (a), cholesterol (b), alanine aminotransferase (ALT) (c), aspartate aminotransferase (AST) (d), creatine kinase $(\mathrm{CK})(\mathbf{e})$ and sodium $\left(\mathrm{Na}^{+}\right)$to potassium $\left(\mathrm{K}^{+}\right)$ratio $(\mathrm{Na} / \mathrm{K})(\mathbf{f})$ in not infected (NI) fish exposed to $0 \%$ of $\mathrm{GLS}(\mathrm{NI}-\mathrm{C})$ and an extreme dose of GLs (NI-13) and infected fish (I) fed feed with 0\% of GLs-containing raw ingredient (I-C), 3.6\% (I-3.6) and 13\% (I-13). Blood plasma profiling was performed on 15 individuals from NI-C and 16 individuals from NI-13 in Trial 1, and 9 fish from each of the groups in Trial 2. Asterisks shown between $\mathrm{NI}$ and I groups refer to statistical differences of $\mathrm{NI}-\mathrm{C}$ and $\mathrm{NI}-13$ as one group vs I-C, I-3.6 and I-13 as the other group. Asterisks shown above bars denote significant differences between two groups. ${ }^{*} P<0.05,{ }^{*} P<0.01$

\section{Microarray analyses}

Microarray analyses were performed on liver, distal kidney and muscle samples from the NI-C and NI-13 fish from Trial 1. The criteria for differentially expressed genes (DEGs) were selected by comparison of the test NI-13 group to NI-C, with $\log 2-\mathrm{ER}>0.6$ and $P<0.05$. Magnitude of diet-induced changes was similar in all tissues, while the number of DEGs that met our criteria was highest in the liver (232), followed by the distal kidney (188) and the muscle (156).

\section{Liver}

Genes with roles in cell cycle and related processes (chromatin organisation regulation, DNA replication and repair) comprised a large part of differentially expressed genes (Table 5). Increased expression was shown by several genes involved in the negative regulation of cellular proliferation (e.g. cullin 1b, btg1, c ostars family protein abracl) while a suite of genes coding for proteins required for cell cycle, DNA replication and cellular division (e.g. securin, condensin complex subunit 3 and cyclins G2/mitotic-specific cyclin-B1 and cyclin-A2) were downregulated. Activation of detoxification genes from both phase-1 (oxidation, reduction, and hydrolysis reactions) and phase-2 (conjugation reactions that increase water solubility of products generated by phase- 1 enzymes) pathways was observed (Table 5). Phase-1 monooxygenases cytochrome P450 24A1 (cyp24a1) may oxidise either xenobiotics or endogenous compounds. GLs-enriched diet also activated epoxide hydrolase 

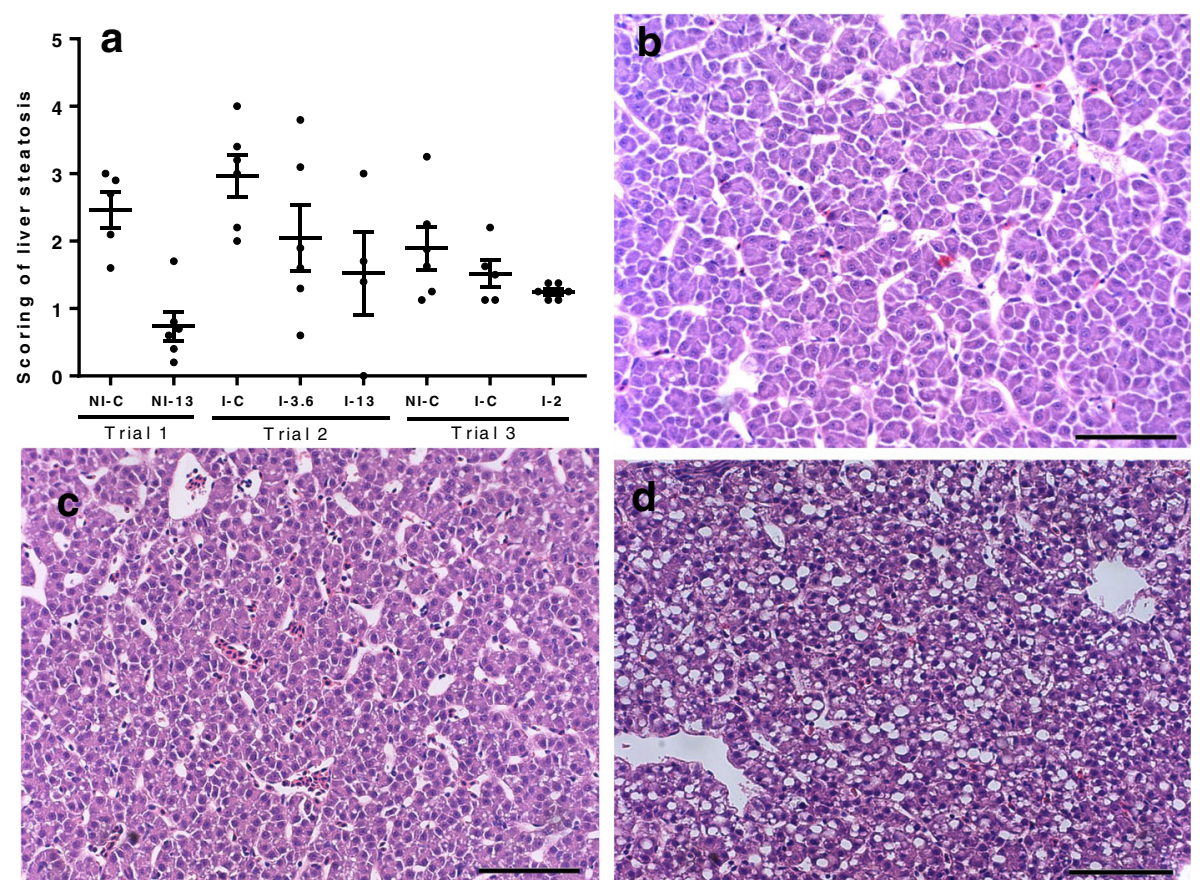

Fig. 2 a Scoring of liver steatosis by light microscopy in Trial 1, 2 and 3. Liver sections from Trial 1 (NI-C and NI-13), Trial 2 (I-C, I-3.6 and I-13) and Trial 3 (NI- C, I-C and I-2) were scored from 0 to 5 [88], based on the degree of vacuolization in the cytoplasm and the degree of distribution of the vacuolated hepatocytes (Additional file 1: Table S2). 4-6 fish in each group were analyzed. Solid black line shows the mean score \pm SEM in each group, and black dots show the individual fish scores. b-d Exemplary images of livers showing different level of steatosis. $\mathbf{b}$ Micrograph of a fish from group 1-3.6 fish (Trial 2) with a score of 0. c Micrograph of a fish from group NI-C fish from Trial 3 with a score of 1. d Micrograph of a fish from group I-C fish from Trial 2 with a score of 3. Scale-bars: $100 \mu \mathrm{m}$

$(e p h x) 1$ and ephx 2 that have roles in the protection from cyclic epoxides. Phase-2 detox metabolism was represented by genes from well-known families responsive to ITCs in mammals [43-46]: UDP Glucuronosyltransferase 1 family polypeptide 67 (ugt1b7), arylamine $N$-acetyltransferase, pineal gland isozyme NAT-10 (ary1), involved in the detoxification of hydrazine and arylamine drugs, and glutathione S-transferase theta (gstt) 1 and gstt3. Stimulation of biotransformation was in line with the slight induction of stress responses witnessed by the upregulation of glucocorticoid receptor and transcription factor jun $b$. Expression of several other genes with important metabolic roles was affected. The leader among the induced genes was CMP-sialic acid transporter (Table 5) involved in the transfer of sialic acid into the Golgi lumen where its conjugation to acceptor molecules takes place. Pyruvate dehydrogenase kinase isozyme $2(p d k 2)$ is a master regulator of metabolic fluxes
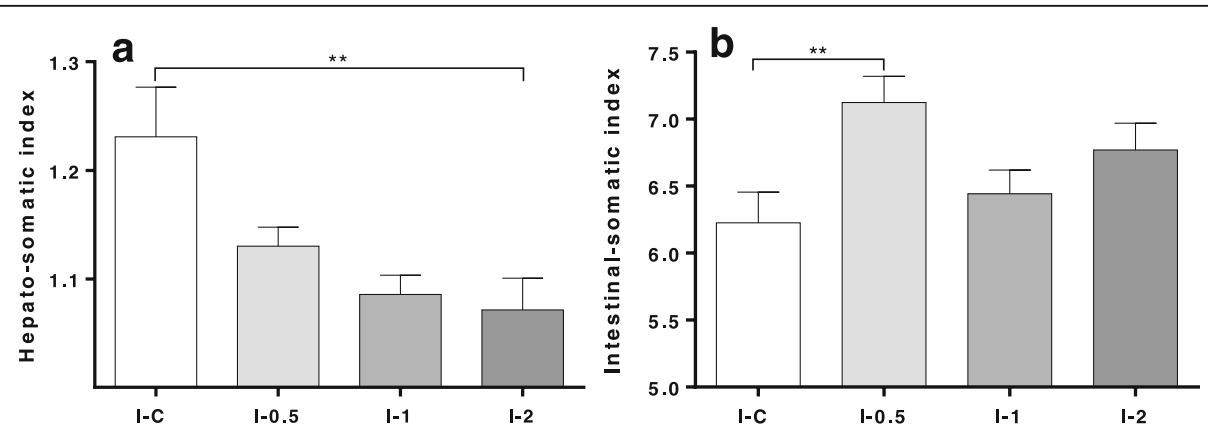

Fig. 3 Organ indices (mean \pm SEM) in lice infected fish (I) fed inclusion levels of $0 \%(I-C), 0.5 \%(I-0.5), 1 \%(I-1)$ and 2\% (I-2) of GLs. a Hepato-somatic indices (HSI). $\mathbf{b}$ Intestinal-somatic indices (ISI). Number of fish in each group is 10. Asterisks denote level of significance between groups: ${ }^{* *} P<0.01$. ISI data was analyzed by One-way ANOVA followed by Tukey's multiple comparisons test, while HSI data was analyzed by the Kruskal-Wallis test followed by the post-hoc Dunn's test 
Table 4 Near infrared spectroscopy (NIR) of Norwegian quality cut (NQC) samples from Trial 3

\begin{tabular}{lllll}
\hline Trial 3 & $\begin{array}{l}14: 0^{\mathrm{a}} \\
(n=10)\end{array}$ & $\begin{array}{l}16: 0^{\mathrm{b}} \\
(n=10)\end{array}$ & $\begin{array}{l}18: 1^{\mathrm{c}} \\
(n=10)\end{array}$ & $\begin{array}{l}22: 6 \mathrm{n}-3^{\mathrm{d}} \\
(n=10)\end{array}$ \\
\hline $\mathrm{I}-0.5$ & $3.23 \pm 0.05^{* *}$ & $15.85 \pm 0.37^{* *}$ & $29.18 \pm 0.38$ & $7.52 \pm 0.20^{* *}$ \\
$\mathrm{I}-1$ & $3.31 \pm 0.07$ & $14.94 \pm 0.47$ & $29.49 \pm 0.76$ & $7.80 \pm 0.20$ \\
$\mathrm{I}-2$ & $3.37 \pm 0.06$ & $15.82 \pm 0.32^{* *}$ & $28.01 \pm 0.65^{*}$ & $7.78 \pm 0.21^{*}$ \\
$\mathrm{I}-\mathrm{C}$ & $5.78 \pm 1.55$ & $12.67 \pm 1.34$ & $23.47 \pm 2.66$ & $8.64 \pm 0.28$ \\
\hline
\end{tabular}

Values are shown as mean \pm SEM. ${ }^{*} P<0.05,{ }^{*} P<0.01$ : significant differences in comparison with control

${ }^{a}$ 14:0 Kruskal-Wallis H-test: $X^{2}=7.8, d f=3, P=0.01$

${ }^{b} 16: 0$ Kruskal-Wallis H-test: $X^{2}=7.8, d f=3, P=0.027 ; 1-0.5$ vs $\mathrm{I}-\mathrm{C} P=0.0096 ; \mathrm{I}-2$ vs $\mathrm{I}-\mathrm{C} P=0.009$

c18:1 Kruskal-Wallis H-test: $X^{2}=7.8, d f=3, P=0.03$

${ }^{2} 22: 6 n-3$ ANOVA: $F_{(3,34)}=4.5 ; 1-0.5$ vs I-C $P=0.0064 ; 1-2$ vs I-C $P=0.05$ ) Lice infected (I) fish were fed inclusion levels of $0 \%$ GLs-containing raw ingredient $(\mathrm{I}-\mathrm{C}), 0.5 \%(\mathrm{I}-0.5), 1 \%(\mathrm{I}-1)$ and $2 \%(\mathrm{I}-2)$. Levels of $14: 0,16: 0,18: 1$, 22:6n-3 are shown, as they were the only parameters that were significantly different in the One-way ANOVA or Kruskal-Wallis test

through the pathways of glucose and lipid metabolism. Also of note was stimulation of bile salt export pump. The observed induction of hepcidin-1 (hepc1) and cytochrome $b$ reductase 1 (cybrd1), the key regulators of iron uptake indicated a decrease of plasma iron levels (Table 5). Porphobilinogen deaminase, involved in heme biosynthesis, and probable cytosolic iron-sulfur protein assembly protein ciao 1, key component of the cytosolic iron-sulfur protein assembly complex, were downregulated. Dietary suppression of a handful of immune genes was observed in the NI-13 group while a few negative regulators of immune responses were found among upregulated genes (data not shown). In contrast, we observed the hepatic induction of four complement system genes (Table 5).

\section{Distal kidney}

A suite of genes involved in xenobiotic metabolism were upregulated (Table 6). NAD $(P) H$ dehydrogenase quinone 1 (nqo1) is a highly-inducible gene coding for a multifunctional antioxidant enzyme that is typically coordinately regulated with other detoxifying genes responsive to ITCs [47]. Several genes that could serve as inhibitor of calcification and renal stone formation included the upregulated fetuin- $A$ [48] (Table 6) and serine-pyruvate aminotransferase, mitochondrial with double metabolic roles, gluconeogenesis in mitochondria and peroxisomal detoxification of glyoxylate (Table 6). The latter function prevents calcium oxalate kidney stone formation [49]. Leptin, which was induced by diet containing GLs, may contribute to the deterioration of renal function through fostering proteinuria and TGF $\beta$-mediated deposition of proteins in the extracellular matrix (ECM) [50] (Table 6). Multiple indications support this claim. Two inhibitors of TGF $\beta$ signalling were suppressed; TGF $\beta$-1-induced transcript 1 protein that also regulates Wnt pathway and TGF $\beta$ receptor III that could act as a decoy receptor involved in capturing and retaining TGF $\beta$ [51]. Increased expression of collagen a3(I) was in parallel with downregulation of procollagen $C$-endopeptidase enhancer 1 that enhances collagen degradation. Upregulation of microfibrillar-associated protein 1, component of the elastin-associated extracellular microfibrils and fibrinogen alpha chain could contribute to deposition of extracellular insoluble fibrils, which cause progressive renal dysfunction [52]. As could be expected, a group of genes that might play protective roles against renal fibrosis was simultaneously activated by exposure to the high dose of dietary GLs, including skiinteracting protein that inhibits TGF $\beta$-mediated responses [53], Wnt-5b that inhibits activation of the canonical (pro-fibrotic) Wnt pathway [54] and matrix metalloproteinase 9 involved in digestion of ECM (Table 6). We also observed regulation of a number of immune genes (data not shown), some of which have known anti-fibrotic properties [55], such as interferon $\gamma$ (ifny) (Table 6) or might act as pro-fibrotic factors and contribute to tissue damage. Regulation of iron metabolism was supported by the expression of two sideroflexins and one ferritin gene (Table 6).

\section{Muscle}

Proapoptotic and inhibitory effects on proliferation in the muscle tissue were inferred from upregulated genes (Table 7), including actin-related protein $2 / 3$ complex subunit $1 B$, involved in the regulation of actin polymerization [56]; Bax that by antagonizing one of the apoptosis repressors accelerates programmed cell death [57], and androgen-induced proliferation inhibitor that plays a role in proliferative arrest [58]. Further support came from the downregulated heparin-binding growth factor 1 that promotes cardiac hypertrophy and smooth muscle cell proliferation [59] (Table 7). Many genes with roles in diverse aspects of muscle-biology were regulated; myosin $\mathrm{Va}$ has a role in actin filament-based movement [60]; four and a half LIM domains protein 1 [61] has a role in muscle development or hypertrophy; sodium/hydrogen exchanger is involved in muscle remodeling [62]; tetranectin is involved in muscle regeneration and muscle cell differentiation [63]; myotubularin plays a role in skeletal muscle maintenance [64]; and protein arginine methyltransferase 5 is required for myogenesis and is also a positive modulator of insulin-mediated glucose uptake in skeletal muscle cells [65]. Active remodeling of intracellular structures in muscle tissue was evidenced by upregulation of stathmin, which disrupts the microtubule array [66] (Table 7). Microtubule-associated protein 1 light chain 3 alpha and tripartite motif-containing $55 b$ that plays regulatory roles in the myofibril assembly [67] were induced by the GLsenriched diet. The suppressed aryl hydrocarbon receptor 2 beta $(a h R 2 b)$ indicated fine-tuning of selected phase-1 
Table 5 Differentially expressed genes in the liver of not infected (NI) salmon fed an extreme dose of GLs-containing raw ingredient ( $\mathrm{NI}-13)$ in comparison to $\mathrm{NI}$ salmon fed $0 \%$ dietary GLs (NI-C). Data are log2-ER

Negative regulation of proliferation
Cullin 16
Btg1
Costars family protein abracl
NOD-like receptor C
HIV-1 Tat interactive protein 2
Nitrilase homolog 2
Positive regulation of proliferation
Transmembrane protein 53
Cell division cycle protein 23 homolog
Cyclin-A2
Arntl2 protein
Ornithine decarboxylase 1
G2/mitotic-specific cyclin-B1
Placenta-specific gene 8 protein

Chromatide segregation and chromosome organization

Haspin
$\mathrm{N}$-acetyltransferase esco 1

Securin

DNA replication

Ribonucleoside-diphosphate reductase large subunit

Chromatin regulation

Histone deacetylase 2

Dnas homolog subfamily C member 2

Lamin B receptor

Condensin complex subunit 3

DNA damage and repair

Uracil-DNA Glycosylase

Ubiquitin carboxyl-terminal hydrolase isozyme L5

Biotransformation/detoxification

Cytochrome P450 24A1, mitochondrial precursor

Glucocorticoid receptor

Arylamine N-acetyltransferase, pineal Gland isozyme NAT-10

Transcription factor jun- $B$

Glutathione S-transferase 3

Glutathione S-transferase theta-1

Epoxide hydrolase 1

Epoxide hydrolase 2 cytoplasmic

UDP Glucuronosyltransferase 1 family polypeptide b7 short isoform

Liver function
Table 5 Differentially expressed genes in the liver of not infected (NI) salmon fed an extreme dose of GLs-containing raw ingredient (NI-13) in comparison to $\mathrm{NI}$ salmon fed $0 \%$ dietary GLs (NI-C). Data are log2-ER (Continued)

\begin{tabular}{lc}
\hline CMP-sialic acid transporter & 2.00 \\
Pyruvate dehydrogenase kinase isozyme 2, mitochondrial & 1.54 \\
precursor & \\
Bile salt export pump & 1.34 \\
Hydroxyacid-oxoacid transhydrogenase, mitochondrial & -1.08 \\
precursor & \\
Novel protein similar to vertebrate scavenger receptor protein & -1.60 \\
Iron metabolism & \\
Hepcidin-1 & 1.60 \\
Cytochrome b reductase 1 & 1.29 \\
Porphobilinogen deaminase & -0.98 \\
Probable cytosolic iron-sulfur protein assembly protein ciao 1 & -0.92 \\
Complement immune response & \\
Complement factor H precursor & 1.33 \\
Properdin P factor 2 & 1.04 \\
Properdin P factor 3 & 0.94 \\
Complement Cla-like protein 4 & 0.88 \\
\hline
\end{tabular}

and -2 cytochrome P450 isoforms, as has been described for the $a h R 2 b$ mammalian counterpart [68] (Table 7). Glutathione transferase omega-1 (gsto1) with dual roles in Ca-mediated muscle contraction, and cellular redox homeostasis as phase-2 biotransformation enzyme [69] was also upregulated (Table 7). The gene 6-phosphogluconolactonase (pgls), coding for an enzyme required for the functioning of the pentose phosphate pathway when the rate of oxidation of NADPH is accelerated [70], was also induced. Increased expression of pgls could contribute to decreased lifetime of 6-phosphogluconolactone, its highly reactive and potentially toxic substrate. Alcohol dehydrogenase class-3 (adh3), also induced, constitutes the primary defence mechanism against formaldehyde damage and may also indirectly mediate protection of proteins against oxidation [71]. Gene encoding heme oxygenase 1 (ho-1) that has important antioxidant and cytoprotective activities was the most highly induced gene by dietary GLs in muscle (Table 7). Previously, it was shown that ITCsmediated induction of heme degrading HO-1 exerts protective effects in kidney [72]. Together with activation of uroporphyrinogen decarboxylase, involved in heme biosynthesis, these findings suggest increased turnover of heme under GLs exposure.

\section{qPCR analyses}

qPCR analyses were used to validate microarray data and, in addition, compare responses of lice-challenged salmon under the low (3.6\%) and extreme dose (13\%) of GLs to lice free and lice infected fish given control feed. 
Table 6 Differentially expressed genes in distal kidney of not infected (NI) salmon fed an extreme dose of GLs-containing raw ingredient (NI-13) in comparison to $\mathrm{NI}$ salmon fed $0 \%$ dietary GLs (NI-C). Data are log2-ER

\begin{tabular}{|c|c|}
\hline & $\log 2-E R$ \\
\hline \multicolumn{2}{|l|}{ Biotransformation, detoxification } \\
\hline Solute carrier family 22 member 2 & 1.41 \\
\hline$N A D(P) H$ dehydrogenase quinone 1 & 1.26 \\
\hline Serine-pyruvate aminotransferase, mitochondrial precursor & 1.24 \\
\hline Glutamate-cysteine ligase catalytic subunit & 0.95 \\
\hline Epoxide hydrolase 2 & -0.90 \\
\hline \multicolumn{2}{|l|}{ Oxidation-reduction processes } \\
\hline Sarcosine dehydrogenase & 1.11 \\
\hline Ubiquinol-cytochrome c reductase core I protein & 1.02 \\
\hline Cytochrome B & -0.94 \\
\hline \multicolumn{2}{|l|}{$\begin{array}{l}\text { Regulation of fibrosis and kidney stone formation, } \\
\text { protection from injury }\end{array}$} \\
\hline 4-hydroxyphenylpyruvate dioxygenase & 2.43 \\
\hline Deltex-3-like & 1.32 \\
\hline Leptin & 1.22 \\
\hline Solute carrier family 13 member 3 & 1.05 \\
\hline Fetuin-A & 1.03 \\
\hline Interferon $y$ & 0.99 \\
\hline Ski-interacting protein & 0.97 \\
\hline Sulfide quinone reductase-like (Yeast) & -1.08 \\
\hline Serine/threonine/tyrosine-interacting protein & -1.15 \\
\hline Sparc precursor & -1.17 \\
\hline Relaxin-3 & -2.01 \\
\hline \multicolumn{2}{|l|}{ Extracellular matrix components and regulation } \\
\hline Fibrinogen alpha chain & 1.07 \\
\hline Wnt-5b & 1.06 \\
\hline Collagen a3(l) & 0.98 \\
\hline Microfibrillar-associated protein 1 & 0.86 \\
\hline Transforming growth factor, beta (TGFB)- receptor III & -1.02 \\
\hline $\begin{array}{l}\text { Transforming growth factor beta (TGF } \beta \text { )-1-induced } \\
\text { transcript } 1 \text { protein }\end{array}$ & -1.14 \\
\hline \multicolumn{2}{|l|}{ Proteolysis } \\
\hline Matrix metalloproteinase 9 & 1.15 \\
\hline OTU domain-containing protein $6 B$ & 0.90 \\
\hline Prepro-cathepsin C & 0.86 \\
\hline Proteasome subunit alpha type-1 & 0.83 \\
\hline Procollagen C-endopeptidase enhancer 1 & -0.92 \\
\hline N-acetylated alpha-linked acidic dipeptidase-like 1 & -1.01 \\
\hline Adamts 15 & -0.88 \\
\hline \multicolumn{2}{|l|}{ Iron homeostasis } \\
\hline Sideroflexin-2 & 0.89 \\
\hline Sideroflexin-4 & 0.84 \\
\hline Ferritin, middle subunit & 0.83 \\
\hline
\end{tabular}

Three complement genes that were not measured by the microarray in liver were analyzed by qPCR (complement c3 (c3), complement c5 (c5) and complement component $1 Q$ binding $(c 1 q b p))$, as several other genes of the complement system indicated complement activation in NI13 (Table 5). Microarray results shown next to qPCR results of NI-13 in Figs. 4, 5 (two first bars), revealed high concordance between the two platforms. Ary1, involved in detoxification, and complement factor $H(c f h)$ and $c 3$, involved in the complement immune response, showed similar level of activation in lice challenged fish. Cyp24a1, a phase-1 detoxification gene and a complement regulator c1qbp were significantly (cyp24a1: $t$-test: $t_{(15)}=2.2, P=$ 0.04; c1qbp: $t$-test: $\left.t_{(15)}=2.4, P=0.03\right)$ responsive to the high dose of GLs without lice (NI-13). pdk2 was significantly induced only in I-C ( $t$-test: $\left.t_{(15)}=3.121, P=0.007\right)$ group. Tyrosinedegrading 4-hydroxyphenylpyruvate dioxygenase $(h p d)$ was the most highly induced gene in NI-13 on the distal kidney microarray. Elevated levels of tyrosine in the absence of HPD activity are toxic to kidney [73, 74]. qPCR analyses revealed most statistically significant ( $t$-test: $\left.t_{(15)}=4.2, P=0.0007\right)$ upregulation of $h p d$ in I-3.6 salmon. I-13 group showed highest level of solute carrier family 13 member 3-like (slc13a3), while during infestation, ifny and integrator complex subunit 7 (ints7) were most highly induced under the lower dose of GLs, in I-3.6 salmon. Ifny, also highly induced in NI-13, is protective against renal injury induced by arsenite by modulation of detoxification pathways [75] and experimental renal fibrosis following chemotherapeutic exposure, explained by increasing the viability of renal tubular cells [76]. Slc13a3 is highly expressed on the basolateral membrane of proximal kidney tubule cells, contributes to heavy metal detoxification $[77,78]$ and is involved in the selective uptake of Krebs cycle intermediates [77]. Ints7 plays a role in the DNA damage response pathway that typically results in cell cycle arrest [79]. qPCR analysis revealed appreciable induction of leptin in I-13 (6-fold compared to NI-C) while I-C and I3.6 groups showed slight downregulation. The knockout of abhydrolase domain-containing protein 6 (abhd6), which was significantly $\left(t\right.$-test NI-C vs I-13: $t_{(15)}=2.1, P=0.05$; IC vs I-13: $\left.t_{(16)}=3.1, P=0.0074\right)$ induced in I-13 fish, results in downregulation of genes involved in de novo fatty acid synthesis and lipogenesis in murine kidney [80].

\section{Discussion}

The interest for GLs and their breakdown products in Atlantic salmon aquaculture lies in their parasiticidal potential against salmon louse, alongside beneficial effects related to the improvement of the antioxidant status and detoxification abilities. However, based on knowledge from vertebrate studies, both adverse and positive effects of dietary GLs could be anticipated. An undesired consequence, most pronounced at the extreme dietary level of 
Table 7 Differentially expressed genes in the muscle of not infected (NI) salmon fed an extreme dose of GLs-containing raw ingredient (NI-13) in comparison to $\mathrm{NI}$ salmon fed $0 \%$ dietary GLs (NI-C). Data are log2-ER

Positive regulation of proliferation
Ccr4-not transcription complex subunit
Placenta-specific gene 8 protein
Haspin

$\log 2-E R$

Negative regulation of proliferation, apoptosis

Actin-related protein 2/3 complex subunit $1 B$

Kruppel-like factor 11

Androgen-induced proliferation inhibitor

Tumor necrosis factor receptor superfamily member $1 \mathrm{~A}$

Bax

Caspase-activated DNase

Cyclin-D-binding Myb-like transcription factor 1

DNA replication

Nuclear factor 1

DNA replication licensing factor $\mathrm{mcm} 3$

DNA replication licensing factor $\mathrm{mcm} 5$

DNA damage and repair

E3 sumo-protein ligase nse2

TFIIH basal transcription factor complex helicase XPB subunit

FACT complex large subunit

Ubiquitin-conjugating enzyme E2 T

Nucleotide metabolism

Adenylosuccinate synthetase isozyme 2

Deoxycytidylate deaminase

$-0.98$

$-1.22$

Muscle metabolism, myogenesis

Acta1 protein

Microtubule-associated protein 1 light chain 3 alpha

Tetranectin

1.26

1.17

1.07

Protein arginine methyltransferase 5

Myosin 1

1.03

1.00

Tripartite motif-containing 556

0.84

Four and a half LIM domains protein 1

$-0.81$

Heparin-binding growth factor 1

$-0.85$

Myosin Va

$-1.03$

Sodium/hydrogen exchanger

$-1.45$

Myotubularin

Negative regulation of myogenesis

Cardiomyopathy associated 5 like

Stathmin

Histone deacetylase 4

Biotranformation, detoxification

6-phosphogluconolactonase
Table 7 Differentially expressed genes in the muscle of not infected (NI) salmon fed an extreme dose of GLs-containing raw ingredient (NI-13) in comparison to $\mathrm{NI}$ salmon fed $0 \%$ dietary GLs (NI-C). Data are log2-ER (Continued)

\begin{tabular}{lc}
\hline Glutathione transferase omega-1 & 1.10 \\
Cytochrome b-cl complex subunit 6, mitochondrial & 1.01 \\
Alcohol dehydrogenase class-3 & 0.84 \\
Aryl hydrocarbon receptor 2 beta & -0.86 \\
Cytochrome P450 1A1 & -0.86 \\
Iron metabolism & \\
Heme oxygenase 1 & 1.69 \\
Proton-coupled folate transporter & 1.29 \\
NADH-cytochrome b5 reductase 1 & 0.94 \\
Uroporphyrinogen decarboxylase & 0.84 \\
NADPH-dependent diflavin oxidoreductase 1 & -0.96 \\
Sideroflexin-2 & -1.17 \\
\hline
\end{tabular}

GLs, was the observed reduction in growth seen in Trial 2. Microarray profiling proposed molecular players behind the reduction in growth mediated by high levels of dietary GLs. Higher mRNA levels in NI-13 in comparison to control were seen for a number of genes involved in the negative regulation of proliferation in both liver and muscle. This was in line with a number of suppressed genes with roles in the development, maintenance and hypertrophy of muscle in the transcriptome of fish under the extreme exposure to GLs. In contrast, the

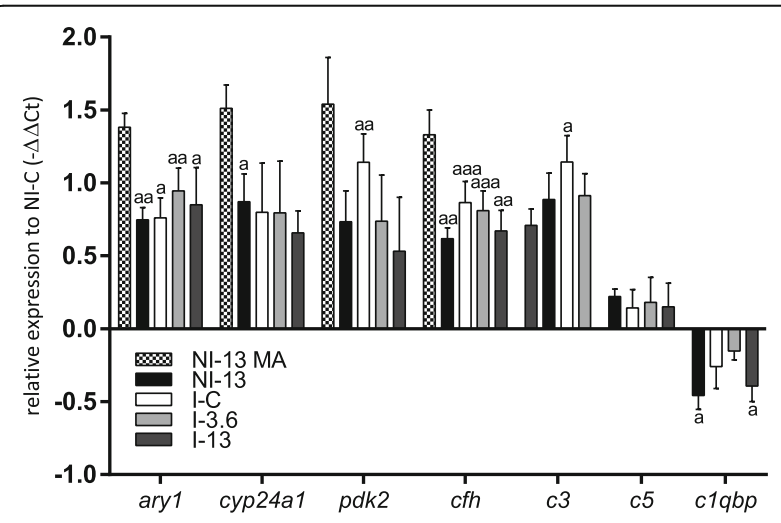

Fig. 4 Hepatic gene expression of ary1, cyp24a1 and pdk2 with roles in metabolic adaptation to nutrient availability, complement regulator $\mathrm{ch}$, complement components $c 3$ and $c 5$, and complement regulator $c 1 q b p$ measured by $\mathrm{qPCR}$ and shown as mean $-\Delta \Delta \mathrm{Ct} \pm \mathrm{SEM}$. The first bar for each gene shows the logER value measured by microarray in not infected (NI) fish ( $n=5$ ) fed 13\% of the GLs-containing raw ingredient (NI-13). Gene expression in infected (I) fish fed increasing levels of GLs-containing raw ingredient, $0 \%(I-C), 3.6 \%(I-3.6)$ and $13 \%(I-13)$, were measured by qPCR. The zero is set to NI fish fed 0\% dietary GLs (NI-C). Number of fish in each group is 9. The letter "a" denotes significant expression difference to NI-C, "aaa" when $P<0.001$, "aa" when $P<0.01$ and "a" when $P<0.05$ 
negative effect on growth was not shown in Trial 3, with up to $2 \%$ of the GLs-containing raw ingredient included in the feed. With respect to other potential beneficial effects of GLs, of note was the reduction of liver steatosis (Fig. 2a) measured even at a low level of GLs (I-2) and decrease of HSI in I-2 (Fig. 3a). In Trial 3, an increase in ISI with the increasing level of GLs was revealed, being highest and significant at the lowest inclusion level of GLs (Fig. 3b). Interestingly, fillet quality traits profiled by NIR for I-0.5, I-1 and I-2 fish revealed minor differences (Table 4).

Microarrays of the distal kidney of NI-13 was characterized by the concerted activation of DNA damage response genes (Table 6), and suggested activation of anti-fibrotic responses and those implied in the prevention of renal stone formation. This was not reflected in the level of plasma indicators of tissue damage (ALT, AST and CK) in Trial 1 (Fig. 1). In fact, most had lower values in NI-13 compared to NI-C. Furthermore, reduced enzyme levels in fish from Trial 2 in comparison to fish from Trial 1 were likely the reflection of lowered tissue metabolic activity during the lice challenge, possibly most affecting muscle, as judged by the drop in CK levels. Nevertheless, evidence produced with qPCR, particularly leptin data (Fig. 5), pointed out that I-13 fish stand an increased risk of developing renal pathophysiology in case

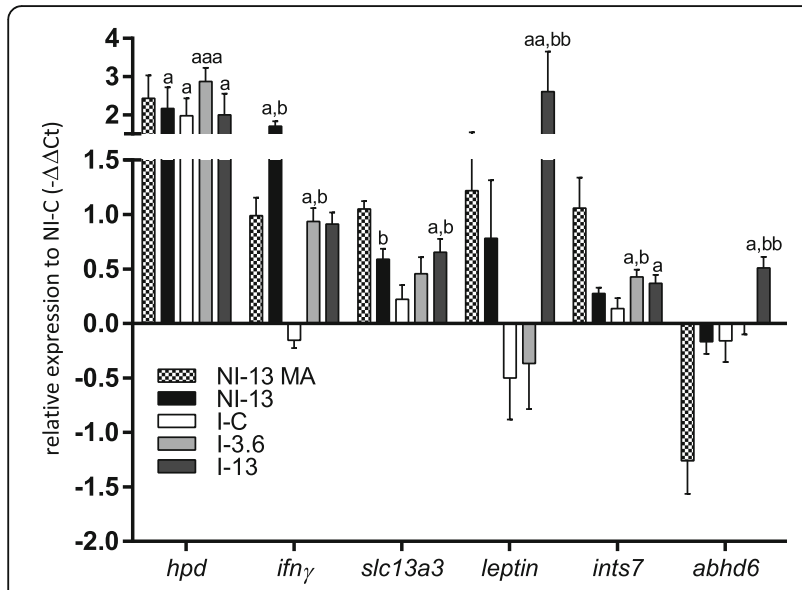

Fig. 5 Renal gene expression of hpd from the tyrosine breakdown pathway, anti-fibrotic ifny, s/c13a3 involved in the maintenance of citrate levels, pro-fibrotic leptin, the DNA damage response gene ints7, and $a b$ hd 6 with functions in the regulation of lipogenesis in kidney, measured by $\mathrm{qPCR}$ and shown as mean $-\Delta \Delta C \mathrm{Ct} \pm \mathrm{SEM}$. The first bar for each gene shows the logER value measured by microarray in not infected (NI) fish $(n=5)$ fed feed with 13\% inclusion level of GLs-containing raw ingredient (NI-13). Gene expression in infected (I) fish fed increasing levels of GLs-containing raw ingredient, $0 \%(I-C), 3.6 \%$ $(1-3.6)$ and 13\% (I-13), were measured by GPCR. The zero is set to NI fish fed $0 \%$ dietary GLs (NI-C). Number of fish samples in each group is 9. The letter "a" denotes significant expression difference to NI-C, and "b" denotes significant expression difference to $1-C$, "aaa" when $P<0.001$, "aa/bb" when $P<0.01$ and "a/b" when $P<0.05$ of prolonged simultaneous exposure to high levels of the two stressors. The increase of the $\mathrm{Na} / \mathrm{K}$ ratio in $\mathrm{I}-13$ (Fig. 1) could be seen as a warning sign that suggested adverse alteration of the hydromineral balance in this fish in comparison to I-C. However, the high expression level of leptin and abhd6 seen in I-13 (Fig. 5) completely diminished in I-3.6, and moreover, the moderate level of GLs promoted the expression of ints7 and ifny, the latter of which has numerous documented protective roles in the mammalian kidney.

Expectedly, GLs stimulated the expression of genes involved in detoxification. In contrast to the long-held notion that GLs-derived ITCs selectively activate phase-2 while suppressing phase-1 detoxification pathways [26, 81], our data revealed activation of a diverse group of genes related to both pathways. In addition to the welldocumented antioxidant properties of ITCs related to induction of phase-2 enzymes [26], their pro-oxidant properties are likely related to the simultaneous induction of phase-1 enzymes. Phase-1 detoxification is dominated by reactions involving cytochrome $\mathrm{P} 450$ enzymes, which are abundantly present in the endoplasmic reticulum in liver and kidney. Hepatic induction of cyp24a1 and two epoxide hydrolases (ephx1 and 2) from phase-1 (Table 5) occurred in parallel with the suppression of ephx2 in kidney (Table 6), and cytochrome p450 1a1 and ahR2b, which regulates P450 enzymes, in muscle (Table 7). Activation of genes from phase-2 metabolism was prevalent in all three tissues. The extreme GLs-enriched diet induced key genes required for glutathione (GSH) based detoxification processes that result in formation of water-soluble products that can be easily excreted. Glutamate-cysteine ligase catalytic subunit encoding the first rate-limiting enzyme of glutathione synthesis was upregulated in distal kidney (Table 6) while glutathione transferases that catalase conjugation of GSH to xenobiotic products of phase-1 detoxification steps, were induced in liver (gstt1 and gstt3) (Table 5) and muscle (gsto1) (Table 7). Furthermore, observed increase in the expression of nqo1 in distal kidney (Table 6), ary 1 and ugt1b7 in liver (Table 5), and pgls and adh3 in muscle (Table 7), may all contribute to the better protection against xenobiotics in fish exposed to dietary GLs. Another potentially important effect of GLs is regulation of iron metabolism in all three tissues. Levels of bioavailable iron are determined by intestinal absorption and macrophage recycling of iron from hemoglobin. Hepcl is a liver peptide that modulates intestinal iron absorption and acts to attenuate iron release from tissue macrophages and hepatocytes. Hepatic induction of hepcl and cybrd1 (Table 5) in fish exposed to GLs could result in increased iron sequestration in liver, thus lowering iron plasma levels. Most of the intracellular iron is used in mitochondria for heme biosynthesis or in cytoplasm for the assembly of iron-sulfur clusters that are incorporated into extra- 
mitochondrial iron/sulfur containing proteins. Cellular iron status determines the extent of iron-sulfur cluster assembly and thereby regulates expression of genes for iron storage, transport, and utilization. Concomitant downregulation of porphobilinogen deaminase, involved in heme biosynthesis provided solid indication that iron excess stimulates cytosolic FeS cluster biogenesis (Table 5). Renal induction of ferritin, involved in iron sequestration within cells, additionally supported possibility that the access of iron to circulation was reduced by GLs (Table 6). Furthermore, the most highly induced gene in muscle was ho-1 (Table 7), an enzyme with the key role in degradation of heme into iron and biliverdin, which is then converted to bilirubin [82]. Iron tissue dynamics within salmonid hosts is believed to play an important role in the outcome of lice infections [16]. Coordinated and early changes in the expression of genes involved in metabolism of iron and erythropoiesis in spleen, head kidney and liver were seen in lice-infected Atlantic salmon [83, 84]. The resistant pink salmon showed highly diverse iron sequestration and homeostasis mechanisms, including an early upregulation in the head kidney of hepcl, ho-1 and several genes involved in iron tissue storage and sequestering of iron from blood [16]. Bilirubin that is predominantly formed by breakdown of heme present in hemoglobin showed highest level in the bestprotected infected group (I-3.6, Fig. 1). The observed increase in bilirubin was likely not caused by liver damage, as levels of ALT and AST went down during the lice infection. With respect to protection against the parasite, of note are also decreased levels of cholesterol in all infected dietary groups in comparison to NI fish. Cholesterol deprivation of lice by the infected host can limit their growth. This was also implied in our recent study where estrogen-mediated protection was associated with a regulation of skin genes involved in cholesterol metabolism, among several other potentially beneficial processes [18]. Lepeophtheirus salmonis, which is an obligate parasite, lacks genes required for the cholesterol biosynthesis encoded in its genome (Prof. Frank Nilsen, personal communication).

Profiling of skin of lice-infected fish from the GLs feeding trial revealed reduced number of attached lice and massive activation of antiviral responses, likely including IFN-mediated responses [17]. The type and magnitude of immune responses at the site of parasite attachment in skin $[13,15]$ and in internal immune organs [85] contribute to susceptibility to L. salmonis in Atlantic salmon. Several complement system genes responded to GLs in NI-13 - this type of immune system preconditioning by diet could be helpful upon parasite encounter.

\section{Conclusions}

Our findings encourage future use of GLs-based feeds due to their beneficial effects on the expression of genes with detoxifying and iron-regulatory roles in multiple fish tissues. The further refinement of anti-lice functional feeds will require understanding of how the beneficial processes can be promoted to achieve protection against lice while not decreasing growth or posing any adverse effects on tissue functions.

\section{Methods \\ Preparation of feeds and fish trials, production of feeds and copepodids}

The trials were approved by the National Animal Research Authority, in line with the "European Convention for the Protection of Vertebrate Animals used for Experimental and other Scientific purposes" were performed at Ewos Innovation in Dirdal, Norway. Feeds with various inclusion levels of glucosinolates (GLs) were produced at the Ewos Innovation plant in Dirdal, Norway. The GLs were added to feeds by spraying the powdered raw ingredient onto the base pellet under vacuum conditions. Air pressure was then allowed to return to normal and the GLscontaining powder was sucked into the core of the pellet. All diets had a pellet size of $5 \mathrm{~mm}$. An overview of trials, harvested samples and applied analysis methods are shown in Additional file 1: Table S1. The study groups were denoted by trial (Trial 1 and Trial 2), treatment (not infected - NI or infected - I) and the level of ingredient $(0 \%-C, 3.6$ or $13 \%$ inclusion level).

The graphical overview of Trial 1 and Trial 2 is shown in Fig. 6. Fish in six tanks with 18 fish in each were fed the $0 \%$ GLs control feed for one month (acclimation) before separation of fish into two groups (Trial 1). Fish in three tanks continued on the control feed (NI-C) while fish in three other tanks were given the $13 \%$ GLs feed (NI-13) during 17-18 days. At the end of this period weight and length measurements ( $n=18$ in each group) and samples of liver, muscle and distal kidney $(n=9$ in each group) were taken. Tissue samples were placed in RNAlater (Ambion', Austin, TX, USA) and stored at $4{ }^{\circ} \mathrm{C}$ for $24 \mathrm{~h}$ and then stored at $-80{ }^{\circ} \mathrm{C}$ until further analyses. In addition, 5 liver samples from each group were placed in neutral buffered formalin for histology. In Trial 2, fish in tank triplicates received control diet, and diets enriched with 3.6 and $13 \%$ of the GLs-containing raw ingredient during three weeks. There were 90 fish in each feed group (control, 3.6 and 13). The amount of uneaten pellets was recorded weekly to calculate the feed intake for each of the feeds over three weeks. After this, all 15 tanks were given a control feed (EWOS Opal) for 10 days, and number of fish in each group was reduced to 60 . This was followed by feeding fish ( $n=20$ in each tank) control feed, 3.6 and 13\% GLs enriched feeds in tank triplicates for 12 days (pre-infection period), and throughout the 31-35 day period of $L$. salmonis infection (post-infection period). During a sampling period of 4 days, number, stage and 

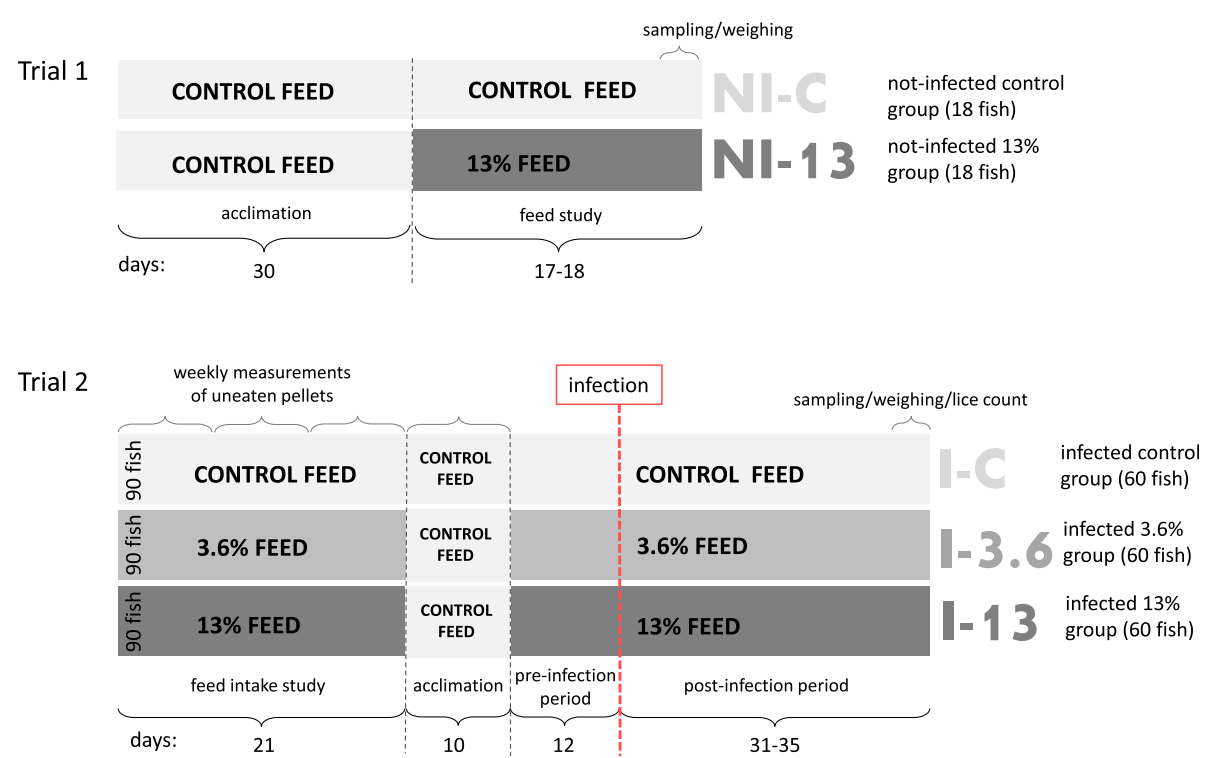

Fig. 6 Experimental setup of Trial 1 and Trial 2 (modified from [17]). Trial 1. Feed study. To study responses of the feed (without infection), Atlantic salmon were fed control feed and high level (13\%) of GLs-containing raw ingredient. All fish received control feed for 30 days during the acclimation period. Sampling of tissues and weighing of the fish from two groups [not-infected control group ( $\mathrm{NI}-\mathrm{C}$ ) and not-infected 13\% group (NI-13)] were performed 17-18 days after feeding experimental feeds. Trial 2. Feed intake and lice challenge study. Atlantic salmon were exposed to feeds containing 0,3.6 and 13\% of GLs for 21 days. Control feed was then fed for 10 days during the acclimation period. The trial continued with fish exposed to control, and 3.6 and $13 \%$ GLs feeds for 12 days (pre-infection period). The tissue sampling, weighing and lice counting from the three dietary groups [infected fish fed control feed (I-C), infected fish fed 3.6\% GLs feed (I-3.6) and infected fish fed 13\% GLs feed (I-13)] challenged with L. salmonis (50 copepodids per fish) were accomplished after 31-35 days of infection (post-infection period)

gender of lice on each fish were recorded. Furthermore, liver and distal kidney tissues were sampled in RNAlater from 9 fish in each group. In addition, 4-6 liver samples from each group were placed in neutral buffered formalin for histology. The treatment groups tested in this part were named: infected control (I-C), infected 3.6 (I-3.6) and infected 13 (I-13). Fulton's condition factor was calculated by the formula: $\left(100 \mathrm{BWFL}^{-3}\right)$ [86] in both Trial 1 and Trial 2. Finally, peripheral blood from the caudal vein was collected into heparinized vacutainers from fish in each group in Trial $1(n=15-16)$ and Trial $2(n=9)$. Fish tanks used in both trials were $500 \mathrm{l}$ circular flowthrough tanks with an average temperature of $8.7{ }^{\circ} \mathrm{C}$ and 27.4 ppt salinity.

Trial 3 was performed in August 2013 with low inclusion levels of the GLs-containing raw ingredient $(0,0.5$, 1 and $2 \%)$. Groups in this trial were thus infected control (I-C), infected 0.5\% (I-0.5), infected 1\% (I-1) and infected $2 \%$ (I-2) and each group of fish was allocated into three tank replicates with 23-26 fish in each tank. Tank conditions, feeding regime and infection of fish with copepodids were similar to the infection study in Trial 1 and 2 [17], but fish were fed the experimental diets for 23 days before lice challenge, and sampling was performed after 26-28 days of infection. At this time point, Norwegian Quality Cut (NQC) samples were harvested from 10 fish from each group according to the standard procedure. Liver samples (4-6) from each group were placed in neutral buffered formalin for histology. In addition, hepato-somatic and intestinal-somatic indices were calculated from 10 fish from each group, performed by weighing the liver and intestinal mass of each fish respectively and dividing this value by the fish weight.

Statistical differences of weights, CFs and organosomatic indices were assessed by One-way ANOVA with subsequent Tukey's multiple comparisons test in the GraphPad Prism Software 6.0 as criteria for Gaussian distribution were met by Shapiro-Wilkes test and in addition the equal variance test (Brown-Forsythe). Students $t$-test was used for analyzing weights and CF in Trial 1. The level of significance for all analyses was set at $P<0.05$.

\section{Challenge with salmon lice}

Challenge trial were performed as described in [17]. In short, the lice population used in Trial 2 and 3 originated from a nearby location (Oltesvik), and were maintained on Atlantic salmon hosts kept in $850 \mathrm{l}$ circular flow tanks at the Ewos Innovation salmon lice lab. Before infection, the copepodid density was measured in a zooplankton counting chamber, where at least 4 samples were counted to ensure accuracy of estimation. Experimental infection was 
performed with 50 copepodids per fish. During the tissue sampling period of 4 days, when most lice had reached the preadult stages, recordings of the exact number, stage and gender of lice on each fish were made.

\section{RNA extraction and gene expression analysis RNA extraction}

Nine tissues samples of approximately $5 \times 5 \mathrm{~mm}$ in size were excised from the fish and put in RNAlater at $4{ }^{\circ} \mathrm{C}$ and then to $80{ }^{\circ} \mathrm{C}$ until further use. Total RNA extraction was performed by the RNeasy Mini Kit (Qiagen) and Trizol (GIBCO, Life Technologies). In brief, Trizol (GIBCO, Life Technologies, Carlsbad, CA, USA), zirconium oxide beads (VWR, Oslo, Norway) and approximately $50 \mathrm{mg}$ of tissue was homogenized in FastPrep-24 homogenizer (MP Biomedicals, Santa Ana, CA, USA). Chloroform was added to separate RNA into the supernatant, which was subsequently run through the RNAeasy Mini Kit clean-up procedure provided by Qiagen (Hilden, Germany). The RNA was diluted with $30 \mu \mathrm{l}$ of RNAse free $\mathrm{H}_{2} \mathrm{O}$, concentration was determined by spectrophotometry using NanoDrop ND1000 (Nanodrop Technologies, Wilmington, DE, USA) and stored at $-80^{\circ} \mathrm{C}$. Integrity of RNA was assessed with Agilent 2100 BioAnalyzer (Agilent, Santa Clara, CA, US) and RNA Nano kits, and only samples with RNA integrity number (RIN) of 8 or higher were used for microarray.

\section{Microarray analyses}

All reagents used in the microarray procedure were from Agilent Technologies. Liver, distal kidney and muscle samples $(n=5)$ from fish from each group (NI-C, NI-13) in Trial 1 were analyzed by microarray, and compared to pooled controls of two fish from each diet from the same organ. The test samples and pooled controls were labelled with respectively Cy5 and $\mathrm{Cy} 3,100 \mathrm{ng}$ of RNA per reaction, by using The Two-colour Quick Amp Labelling kits and Gene Expression Hybridization kits. The hybridization step lasted $17 \mathrm{~h}$ at $65^{\circ} \mathrm{C}$ with rotation speed $10 \mathrm{rpm}$, followed by immersion for one minute each in Gene Expression Wash Buffer I at room temperature and subsequently washing in Gene Expression Wash Buffer II at $37{ }^{\circ} \mathrm{C}$. By scanning slides using GenePix Personal 4100A scanner with 5 um resolution and manually adjusted laser power, an equal intensity ratio between Cy3 and Cy5 channels with minimal oversaturation was achieved. GenePix pro software 6.0 was used for feature extraction, assessment of spot quality, and spot-grid alignment. Low quality spots were flagged by the software, and Lowess normalization of log2-expression ratios (ER) was performed. Differentially expressed genes (DEGs) were selected by comparison with not infected control (NI-C): $\log 2-\mathrm{ER}>0.6$ and $P<0.05$ in at least one group. Nofima's bioinformatics system (STARS) [87] was used for data analyses.

\section{CDNA synthesis and qPCR protocol}

For qPCR analysis, RNA from 9 fish from the Trial 1 groups; NI-C, NI-13, and Trial 2 groups; I-3.6, I-13 and I-C, were used. NI-C from Trial 1 was deemed as an appropriate control for fish in Trial 2 as both trials took place under the same environmental conditions in the Salmon Lice Lab in Dirdal and with negligible time difference; less than a week passed between the two samplings. RNA was reverse transcribed to cDNA by using the cDNA Affinity Script (Agilent Technologies, Matriks AS, Oslo, Norway) and protocol provided by the manufacturer. Each reaction consisted of $3 \mu \mathrm{g}$ RNA, $1 \mu \mathrm{l}$ of random primers and $2 \mu$ of oligo DT primers. The synthesized cDNA was diluted 10 times and stored at $-20{ }^{\circ} \mathrm{C}$ until further use. The qPCR reactions were run in duplicates. Each reaction $(12 \mu \mathrm{l})$ contained $4 \mu \mathrm{l}$ of cDNA, $10 \mu \mathrm{M}$ primers and SYBR Green I Master mix (Roche); analyses were run in LightCycler 480 in 96 well plates. Published gene sequences were used to design primers (Additional file 1: Table S3) for quantitative Real Time PCR (qPCR) reactions by CLC Workbench software. Cycling conditions in LightCycler 480 instrument (Roche, Applied Science) were 5 min denaturation step at $95{ }^{\circ} \mathrm{C}, 40$ cycles of denaturation $\left(10 \mathrm{~s}\right.$ at $\left.95{ }^{\circ} \mathrm{C}\right)$, annealing $\left(20 \mathrm{~s}\right.$ at $\left.60{ }^{\circ} \mathrm{C}\right)$ and extension $\left(15 \mathrm{~s}\right.$ at $\left.72{ }^{\circ} \mathrm{C}\right)$, followed by melting curve analysis with measurements of the fluorescence was performed in the temperature range between 65 and $97{ }^{\circ} \mathrm{C}$. The crossing point value was found by using the maximum-second-derivative method (Roche diagnostics), followed by the $-\Delta \Delta \mathrm{Ct}$ method with comparison to reference gene elongation factor 1 alpha $(e f 1 \alpha)$ to find the relative expression of target genes. No signs of gDNA contamination were found by running a subset of RNA samples together with ef1a and SybrGreen. Specificity and efficiency were confirmed by melting curve analysis, agarose gel electrophoresis and two-fold serial dilutions of cDNA for each primer pair in triplicates. PCR efficiency of all genes ranged from 1.96 to 2 . Data were analyzed with students $t$-test in the GraphPad Prism Software 6.0 if criteria for Gaussian distribution were met by Shapiro-Wilkes test. All qPCR data showed equal variance by the BrownForsythe test. If criteria for normality were not met, the Mann-Whitney test was used. The level of significance for all analyses was set at $P<0.05$.

\section{Histology}

Four to six fish selected randomly from each group in Trial 1; NI-C and NI-13, Trial 2; I-C, I-3.6 and I-13, and Trial 3; I-2 group, NI-C and I-C were subjected to histological analysis. Liver samples were fixed in neutral 
buffered formalin for $48 \mathrm{~h}$ with the change of formalin after $24 \mathrm{~h}$ followed by dehydration, paraffin-embedding, sectioning and haematoxylin and eosin (HE) staining by standard histological procedures. The $4 \mu \mathrm{m}$ blinded sections were examined with a Leica DFC 420 microscope equipped with a digital imaging system (Leica Image Analysis). Steatosis scoring was performed by studying five representative fields at $20 \times$ original magnifications, selected randomly. The areas were scored for microvesicular and macrovesicular steatosis following the scoring system and method described in [88] and in Additional file 1: Table S2. A proportion of the liver samples were also stained with Periodic-Acid Schiff (PAS) to exclude glycogen accumulation as a cause of vacuole formation.

\section{Blood plasma profiling}

Blood plasma profiling was performed on 15 individuals from NI-C and 16 individuals from NI-13 in Trial 1, and 9 fish from each of the groups in Trial 2. The full automatic Adria 1800 system in the Central clinical laboratory at the Norwegian University of Life Sciences was used to measure a basic panel of plasma parameters, including ALT (alanine aminotransferase), AST (Aspartate aminotransferase), CK (Creatine Kinase), Cholesterol, $\mathrm{Na}$ (sodium), K (potassium) and bilirubin. All parameters except the ions were found by measuring the optical density at a given absorbance. $\mathrm{Na}$ and $\mathrm{K}$ levels were assessed by the indirect potentiometric procedure. Significant differences for each plasma parameter were analyzed between Trial 1 and Trial 2, treating the groups in each trial as one. Significant differences between were also assessed between the groups in Trial 1 and Trial 2, separately. Data were analyzed by Student's $t$-test or One-way ANOVA with subsequent Tukey's multiple comparisons test in the GraphPad Prism Software 6.0 if criteria for Gaussian distribution were met by ShapiroWilkes test. All parameters showed equal variance in Brown-Forsythe test. If criteria for normality were not met, the Mann-Whitney or the Kruskal-Wallis test was used followed by the post-hoc Dunn's test. The level of significance for all analyses was set at $P<0.05$.

\section{Near infrared spectroscopy}

Near infrared spectroscopy (NIR) is a spectral method based on the fact that different feed components have characteristic NIR absorption bands when exposed to specific wavelengths of infrared light. NIR analysis was performed on NQC samples from 10 individuals from each group from Trial 3 by using the NIR XDS system (Foss, Hillerød, Denmark) at Ewos Innovation, Dirdal. NIR calibration equations were found beforehand by analyzing 1300 NQC samples of fish ranging in size from 0.1 to $6 \mathrm{~kg}$. Reference values were based on well-established internal and external sources. Individual NQC samples were thoroughly grinded in a meat grinder shortly after slaughter. The groups thus analyzed were I-0.5, I- 1 and I-2 in addition to I-C. The levels of ash, energy, fat, moisture, phosphorous, protein, pigment, total monosaturated fatty acids, and a range of fatty acids (PUFA) including: total $n-3$ polyunsaturated fatty acids (PUFA), Total $n$-6PUFA, total PUFA, 14:0, 16:0, 16:1, 18:0, 18:1, 18:2n-6, 18:3n-3, 18:3n$6,18: 4 n-3,20: 1,20: 3 n-3,20: 3 n-6,20: 4 n-3,20: 4 n-6,20: 5 n-$ 3, 22:1, 22:4n-6, 22:5n-3, 22:5n-6, 22:6n-3 were analyzed. Statistical differences were assessed by One-way ANOVA with subsequent Tukey's multiple comparisons test in the GraphPad Prism Software 6.0 if criteria for Gaussian distribution were met by the Shapiro-Wilkes test and in addition the equal variance test (Brown-Forsythe). If criteria for normality were not met, the Kruskal-Wallis test was used followed by the post-hoc Dunn's test. The level of significance for all analyses was set at $P<0.05$.

\section{Additional file}

Additional file 1: Table S1. An overview of samples and analysis methods applied in Trial 1, 2 and 3. Table S2. Scoring of liver steatosis in individual sections based on [88]. Table S3. Primer list. (DOCX 20 kb)

\section{Abbreviations}

abhd6: Abhydrolase domain-containing protein 6; adh3: Alcohol dehydrogenase class-3; ahr2b: Aryl hydrocarbon receptor 2 beta; ALT: Alanine aminotransferase; ary1: Arylamine N-acetyltransferase, pineal gland isozyme NAT-10; AST: Aspartate aminotransferase; clabp: Complement component $1 \mathrm{Q}$ binding; c3: Complement 3; c5: Complement 5; cfh: Complement factor H; ciao 1: Probable cytosolic iron-sulfur protein assembly protein ciao 1; CK: Creatinine kinase; cybrd1: Cytochrome b reductase 1; cyp24a1: Cytochrome P450 24A1; DEGs: Differentially expressed genes; ECM: Extracellular matrix; ephx: Epoxide hydrolase; GLs: Glucosinolates; gsto1: Glutathione transferase omega-1; gstt: Glutathione S-transferase theta; HSI: Hepato-somatic index; ho-1: Heme oxygenase 1; hpd: Tyrosine-degrading 4hydroxyphenylpyruvate dioxygenase; I-0.5: Infected control fed $0.5 \%$ inclusion level of GLs; I-1: Infected control fed 1\% inclusion level of GLs; I-2: Infected control fed $2 \%$ inclusion level of GLs; I-3.6: Infected control fed 3.6\% inclusion level of GLs; I-13: Infected control fed 13\% inclusion level of GLs; I-C: Infected control; ifny: Interferon gamma; ints7: Integrator complex subunit 7; ISI: Intestinalsomatic index; ITCs: Isothiocyanate; K: Potassium; Log2-ER: Log2-Expression Ratios; MA: Microarray; Na: Sodium; NI-13: Not infected fed 13\% inclusion level of GL; NI-C: Not infected control; NIR: Near infrared spectroscopy; NQC: Norwegian quality cut; nqo 1: NAD(P)H dehydrogenase quinone 1; pdk2: Pyruvate dehydrogenase kinase isozyme 2; pgls: 6-phosphogluconolactonase; qPCR: Quantitative PCR; SEM: Standard error of the mean; slc13a3: Solute carrier family 13 member 3-like; tgf $\beta$ : Transforming growth factor beta; ugt1b7: UDP Glucuronosyltransferase 1 family polypeptide b7

\section{Acknowledgements}

This research has been funded by the Research Council Norway, SFI-Sea Lice Research Centre, grant number 20351.

\section{Availability of data and material}

The datasets supporting the conclusions of this article are included within the article and its additional files. Microarray gene expression data files have been deposited to Gene Expression Omnibus (GEO) under accession number GSE84288.

\section{Authors' contributions}

$A K B, H J H, J P, S S, \varnothing E$ and SW were all involved in designing the experiments. JP and SW designed the feeds. AKB produced copepodids, conducted the experiment and counted lice at the end of the challenge trial, while $\mathrm{HH}$ and SS sampled the tissues in all 3 trials. HJH and SS carried out the microarray lab work, and work on organo-somatic indices, NQC profiling and plasma 
data analysis. SS performed and analyzed qPCRs. AK, HJH and SS analyzed the gene expression data. HJH performed and described the histology data while ØE supervised the analysis. SS wrote the first draft, and all authors contributed to the final version of the manuscript. All authors read and approved the final version of the manuscript.

\section{Competing interests}

The authors declare that they have no competing interests.

\section{Consent for publications}

Not applicable.

\section{Ethics approval and consent to participate}

The experimental facilities used in this study at Ewos Innovation, Dirdal, Norway, number 131 was approved by the Norwegian Animal Research Authority 02.02.2012 until 25.01.16. The experiments/procedures have been conducted in accordance with the laws and regulations controlling experiments/procedures in live animals in Norway, e.g. the Animal Welfare Act of 20th December 1974, No 73, chapter VI sections 20-22 and the Regulation on Animal Experimentation of 15th January 1996.

\section{Author details}

${ }^{1}$ Cargill Innovation Center, Sea Lice Research Centre, Oslo, Norway. ${ }^{2}$ Norwegian University of Life Sciences, Faculty of Veterinary Medicine and Biosciences, Sea Lice Research Centre, Oslo, Norway. ${ }^{3}$ Cargill Innovation Center, Dirdal, Norway. ${ }^{4}$ Cargill Innovation Center, Puerto Montt, Chile. ${ }^{5}$ Nofima AS, Ås, Norway.

Received: 13 September 2016 Accepted: 28 November 2016 Published online: 12 December 2016

\section{References}

1. Veterinærinstituttet. Fiskehelserapporten. Oslo: Veterinærinstituttet; 2015. p. 3.

2. Iversen A, Hermansen $\varnothing$, Andreasen $O$, Brandvik R, Marthinussen A, Nystøyl R. Kostnadsdrivere i lakseoppdrett, Nofima rapportserie. 2015. p. 43.

3. Krkosek M, Connors BM, Morton A, Lewis MA, Dill LM, Hilborn R. Effects of parasites from salmon farms on productivity of wild salmon. Proc Natl Acad Sci U S A. 2011;108:14700-4.

4. Krkosek M, Ford JS, Morton A, Lele S, Myers RA, Lewis MA. Declining wild salmon populations in relation to parasites from farm salmon. Science. 2007; 318:1772-5.

5. Costello MJ. How sea lice from salmon farms may cause wild salmonid declines in Europe and North America and be a threat to fishes elsewhere. Proc R Soc Lond B Biol Sci. 2009;276(1672):3385-94.

6. Barker S, Covello JM, Bouchard D, Wolters W, Fast M, Bricknell I. Lice and isav: Are lousy salmon more susceptible? Fish Shellfish Immunol. 2013;34(6): 1637-8.

7. Nylund A, Hovland T, Hodneland K, Nilsen F, Lovik P. Mechanisms for transmission of Infectious salmon anemia (isa). Dis Aquat Organ. 1994;19(2): 95-100.

8. Petterson E, Sandberg M, Santi N. Salmonid alphavirus associated with Lepeophtheirus salmonis (Copepoda: Caligidae) from Atlantic salmon, Salmo salar L. J Fish Dis. 2009;32(5):477-9.

9. Aaen SM, Helgesen KO, Bakke MJ, Kaur K, Horsberg TE. Drug resistance in sea lice: a threat to salmonid aquaculture. Trends Parasitol. 2015;31(2):72-81.

10. Helgesen KO, Bravo S, Sevatdal S, Mendoza J, Horsberg TE. Deltamethrin resistance in the sea louse Caligus rogercresseyi (Boxhall \& Bravo) in Chile: bioassay results and usage data for antiparasitic agents with references to Norwegian conditions. J Fish Dis. 2014;37(10):877-90.

11. Helgesen $\mathrm{KO}$, Horsberg TE. Single-dose field bioassay for sensitivity testing in sea lice, Lepeophtheirus salmonis: development of a rapid diagnostic tool. J Fish Dis. 2013;36(3):261-72.

12. Igboeli OO, Burka JF, Fast MD. Lepeophtheirus salmonis: a persisting challenge for salmon aquaculture. Anim Front. 2014;4(1):22-32.

13. Braden LM, Barker DE, Koop BF, Jones SR. Comparative defense-associated responses in salmon skin elicited by the ectoparasite Lepeophtheirus salmonis. Comp Biochem Physiol Part D Genomics Proteomics. 2012;7(2):100-9.

14. Braden LM, Koop BF, Jones SRM. Signatures of resistance to Lepeophtheirus salmonis include a TH2-type response at the louse-salmon interface. Dev Comp Immunol. 2015;48(1):178-91.
15. Holm H, Santi N, Kjøglum S, Perisic N, Skugor S, Evensen $\varnothing$. Difference in skin immune responses to infection with salmon louse (Lepeophtheirus salmonis) in Atlantic salmon (Salmo salar L.) of families selected for resistance and susceptibility. Fish Shellfish Immunol. 2015;42:384-94.

16. Sutherland BJG, Koczka KW, Yasuike M, Jantzen SG, Yazawa R, Koop BF, Jones SRM. Comparative transcriptomics of Atlantic Salmo salar, chum Oncorhynchus keta and pink salmon O. gorbuscha during infections with salmon lice Lepeophtheirus salmonis. BMC Genomics. 2014;15:200.

17. Jodaa Holm H, Wadsworth S, Bjelland A-K, Krasnov A, Evensen $\varnothing$, Skugor S. Dietary phytochemicals modulate skin gene expression profiles and result in reduced lice counts after experimental infection in Atlantic salmon. Parasit Vectors. 2016;9(1):1-14.

18. Krasnov A, Wesmajervi Breiland MS, Hatlen B, Afanasyev S, Skugor S. Sexual maturation and administration of $17 \beta$-estradiol and testosterone induce complex gene expression changes in skin and increase resistance of Atlantic salmon to ectoparasite salmon louse. Gen Comp Endocrinol. 2015; 212C:34-43.

19. Halkier BA, Gershenzon J. Biology and biochemistry of glucosinolates. Annu Rev Plant Biol. 2006:57:303-33.

20. Nugon-Baudon L, Rabot S. Glucosinolates and glucosinolate derivatives: implications for protection against chemical carcinogenesis. Nutr Res Rev. 1994;7(1):205-31.

21. Brader G, Tas E, Palva ET. Jasmonate-dependent induction of indole glucosinolates in Arabidopsis by culture filtrates of the nonspecific pathogen Erwinia carotovora. Plant Physiol. 2001;126(2):849-60.

22. Bednarek P, Pislewska-Bednarek M, Svatos A, Schneider B, Doubsky J, Mansurova $M$, et al. A glucosinolate metabolism pathway in living plant cells mediates broad-spectrum antifungal defense. Science. 2009;323(5910): 101-6.

23. Hopkins RJ, van Dam NM, van Loon JJ. Role of glucosinolates in insect-plant relationships and multitrophic interactions. Annu Rev Entomol. 2009:54:57-83.

24. Pino-Marambio J, Mordue AJ, Birkett M, Carvajal J, Asencio G, Mellado A, Quiroz A. Behavioural studies of host, non-host and mate location by the sea louse, Caligus rogercresseyi Boxshall \& Bravo, 2000 (Copepoda: Caligidae). Aquaculture. 2007;271(1-4):70-6.

25. Nuñez-Acuna G, Valenzuela-Muñoz V, Marambio JP, Wadsworth S, GallardoEscárate C. Insights into the olfactory system of the ectoparasite Caligus rogercresseyi: molecular characterization and gene transcription analysis of novel ionotropic receptors. Exp Parasitol. 2014;145:99-109.

26. Valgimigli L, lori R. Antioxidant and pro-oxidant capacities of ITCS. Environ Mol Mutagen. 2009;50(3):222-37.

27. Vig AP, Rampal G, Thind TS, Arora S. Bio-protective effects of glucosinolates - a review. LWT Food Sci Technol. 2009;42(10):1561-72.

28. Lam TK, Gallicchio L, Lindsley K, Shiels M, Hammond E, Tao XG, et al. Cruciferous vegetable consumption and lung cancer risk: a systematic review. Cancer Epidemiol Biomarkers Prev. 2009;18(1):184-95.

29. Yuan JM, Stepanov I, Murphy SE, Wang R, Allen S, Jensen J, et al. Clinical trial of 2-phenethyl isothiocyanate as an inhibitor of metabolic activation of a tobacco-specific lung carcinogen in cigarette smokers. Cancer Prev Res. 2016;9(5):396-405

30. Hecht SS, Chung FL, Richie Jr JP, Akerkar SA, Borukhova A, Skowronski L, Carmella SG. Effects of watercress consumption on metabolism of a tobacco-specific lung carcinogen in smokers. Cancer Epidemiol Biomarkers Prev. 1995;4(8):877-84.

31. Higdon JV, Delage B, Williams DE, Dashwood RH. Cruciferous vegetables and human cancer risk: epidemiologic evidence and mechanistic basis. Pharmacol Res. 2007;55(3):224-36.

32. Burel C, Boujard T, Escaffre AM, Kaushik SJ, Boeuf G, Mol KA, Van der Geyten $S$, Kuhn ER. Dietary low-glucosinolate rapeseed meal affects thyroid status and nutrient utilization in rainbow trout (Oncorhynchus mykiss). Br J Nutr. 2000;83(6):653-64.

33. Burel C, Boujard T, Kaushik SJ, Boeuf G, Mol KA, Van der Geyten S, et al. Effects of rapeseed meal-glucosinolates on thyroid metabolism and feed utilization in rainbow trout. Gen Comp Endocrinol. 2001;124(3):343-58.

34. Glencross B, Hawkins W, Curnow J. Nutritional assessment of Australian canola meals. I. Evaluation of canola oil extraction method and meal processing conditions on the digestible value of canola meals fed to the red seabream (Pagrus auratus, Paulin). Aquacult Res. 2004;35(1):15-24.

35. Lakshmy R, Rao PS, Sesikeran B, Suryaprakash P. lodine metabolism in response to goitrogen induced altered thyroid status under conditions of moderate and high intake of iodine. Horm Metab Res. 1995;27(10):450-4. 
36. Schone F, Jahreis G, Lange R, Seffner W, Groppel B, Hennig A, Ludke H. Effect of varying glucosinolate and iodine intake via rapeseed meal diets on serum thyroid hormone level and total iodine in the thyroid in growing pigs. Endocrinol Exp. 1990;24(4):415-27.

37. Tripathi MK, Mishra AS. Glucosinolates in animal nutrition: a review. Anim Feed Sci Technol. 2007;132(1-2):1-27.

38. Gowda S, Desai PB, Hull W, Math AAK, Vernekar SN, Kulkarni SS. A review on laboratory liver function tests. Pan Afr Med J. 2009:3:17.

39. Walker DB. Serum chemical biomarkers of cardiac injury for nonclinical safety testing. Toxicol Pathol. 2006;34(1):94-104.

40. Yousaf MN, Powell MD. The effects of heart and skeletal muscle inflammation and cardiomyopathy syndrome on creatine kinase and lactate dehydrogenase levels in Atlantic salmon (Salmo salar L.). Sci World J. 2012; 2012:741302.

41. Djordjevic B, Kristensen T, Overli O, Rosseland BO, Kiessling A. Effect of nutritional status and sampling intensity on recovery after dorsal aorta cannulation in free-swimming Atlantic salmon (Salmo salar L.). Fish Physiol Biochem. 2012;38(1):259-72.

42. Krasnov A, Skugor S, Todorcevic M, Glover K, Nilsen F. Gene expression in Atlantic salmon skin in response to infection with the parasitic copepod Lepeophtheirus salmonis, cortisol implant, and their combination. BMC Genomics. 2012;13:130

43. Abdull Razis AF, Mohd NN, Konsue N. Induction of epoxide hydrolase, glucuronosyl transferase, and sulfotransferase by phenethyl isothiocyanate in male Wistar albino rats. Biomed Res Int. 2014;2014:391528.

44. Zhao H, Lin J, Grossman HB, Hernandez LM, Dinney CP, Wu X. Dietary isothiocyanates, GSTM1, GSTT1, NAT2 polymorphisms and bladder cancer risk. Int J Cancer. 2007;120(10):2208-13.

45. Zhang Y, Talalay P. Anticarcinogenic activities of organic isothiocyanates: chemistry and mechanisms. Cancer Res. 1994;54(7):1976-81.

46. Talalay P, Fahey JW. Phytochemicals from cruciferous plants protect against cancer by modulating carcinogen metabolism. J Nutr. 2001;131(11):3027-33.

47. Korenori Y, Tanigawa S, Kumamoto T, Qin S, Daikoku Y, Miyamori K, Nagai M, Hou DX. Modulation of Nrf2/Keap1 system by Wasabi 6-methylthiohexyl isothiocyanate in ARE-mediated NQO1 expression. Mol Nutr Food Res. 2013; 57(5):854-64.

48. Evrard S, Delanaye P, Kamel S, Cristol JP, Cavalier E. Vascular calcification: from pathophysiology to biomarkers. Clin Chim Acta. 2015;438:401-14.

49. Danpure CJ, Jennings PR, Leiper JM, Lumb MJ, Oatey PB. Targeting of alanine: glyoxylate aminotransferase in normal individuals and its mistargeting in patients with primary hyperoxaluria type 1. Ann N Y Acad Sci. 1996;804:477-90.

50. Wolf G, Ziyadeh FN. Leptin and renal fibrosis. Contrib Nephrol. 2006;151: $175-83$.

51. Shi $Y$, Massague J. Mechanisms of TGF-beta signaling from cell membrane to the nucleus. Cell. 2003;113(6):685-700.

52. Dember LM. Amyloidosis-associated kidney disease. J Am Soc Nephrol. 2006:17(12):3458-71.

53. Deheuninck J, Luo K. Ski and SnoN, potent negative regulators of TGF- $\beta$ signaling. Cell Res. 2009;19(1):47-57.

54. He W, Dai C, Li Y, Zeng G, Monga SP, Liu Y. Wnt/beta-catenin signaling promotes renal interstitial fibrosis. J Am Soc Nephrol. 2009:20(4):765-76.

55. Oldroyd SD, Thomas GL, Gabbiani G, El Nahas AM. Interferon-gamma inhibits experimental renal fibrosis. Kidney Int. 1999;56(6):2116-27.

56. dos Remedios CG, Chhabra D, Kekic M, Dedova IV, Tsubakihara M, Berry DA, Nosworthy NJ. Actin binding proteins: regulation of cytoskeletal microfilaments. Physiol Rev. 2003;83(2):433-73.

57. Sorenson CM. BCl-2 family members and disease. Biochim Biophys Acta. 2004;1644(2-3):169-77.

58. Zhou Y, Otto-Duessel M, He M, Markel S, Synold T, Jones JO. Low systemic testosterone levels induce androgen maintenance in benign rat prostate tissue. J Mol Endocrinol. 2013;51(1):143-53.

59. Iwamoto R, Mekada E. ErbB and HB-EGF signaling in heart development and function. Cell Struct Funct. 2006;31(1):1-14.

60. Mehta AD, Rock RS, Rief M, Spudich JA, Mooseker MS, Cheney RE. Myosin-V is a processive actin-based motor. Nature. 1999;400(6744):590-3.

61. Chu P-H, Ruiz-Lozano P, Zhou Q, Cai C, Chen J. Expression patterns of FHL/ SLIM family members suggest important functional roles in skeletal muscle and cardiovascular system. Mech Dev. 2000;95(1-2):259-65.

62. Chen L, Chen CX, Gan XT, Beier N, Scholz W, Karmazyn M. Inhibition and reversal of myocardial infarction-induced hypertrophy and heart failure by NHE-1 inhibition. Am J Physiol Heart Circ Physiol. 2004;286(1):H381-7.
63. Wewer UM, Iba K, Durkin ME, Nielsen FC, Loechel F, Gilpin BJ, Kuang W, Engvall $E$, Albrechtsen R. Tetranectin is a novel marker for myogenesis during embryonic development, muscle regeneration, and muscle cell differentiationin vitro. Dev Biol. 1998;200(2):247-59.

64. Taylor GS, Maehama T, Dixon JE. Myotubularin, a protein tyrosine phosphatase mutated in myotubular myopathy, dephosphorylates the lipid second messenger, phosphatidylinositol 3-phosphate. Proc Natl Acad Sci USA. 2000;97(16):8910-5.

65. Iwasaki H, Yada T. Protein arginine methylation regulates insulin signaling in L6 skeletal muscle cells. Biochem Biophys Res Commun. 2007;364(4):1015-21.

66. Rubin $\mathrm{CL}$, Atweh GF. The role of stathmin in the regulation of the cell cycle. J Cell Biochem. 2004;93(2):242-50.

67. Perera S, Holt MR, Mankoo BS, Gautel M. Developmental regulation of MURF ubiquitin ligases and autophagy proteins nbr1, p62/SQSTM1 and LC3 during cardiac myofibril assembly and turnover. Dev Biol. 2011;351(1):46-61.

68. Riddick DS, Lee C, Bhathena A, Timsit YE, Cheng P-Y, Morgan ET, et al. Transcriptional suppression of cytochrome p450 genes by endogenous and exogenous chemicals. Drug Metab Dispos. 2004;32(4):367-75.

69. Dulhunty A, Gage P, Curtis S, Chelvanayagam G, Board P. The glutathione transferase structural family includes a nuclear chloride channel and a ryanodine receptor calcium release channel modulator. J Biol Chem. 2001; 276(5):3319-23.

70. Beutler $\mathrm{E}, \mathrm{Kuhl}$ W. Limiting role of 6-phosphogluconolactonase in erythrocyte hexose monophosphate pathway metabolism. J Lab Clin Med. 1985;106(5):573-7.

71. Haseba T, Duester G, Shimizu A, Yamamoto I, Kameyama K, Ohno Y. In vivo contribution of Class III alcohol dehydrogenase (ADH3) to alcohol metabolism through activation by cytoplasmic solution hydrophobicity. Biochim Biophys Acta. 2006;1762(3):276-83.

72. Tayem Y, Green CJ, Motterlini R, Foresti R. Isothiocyanate-cysteine conjugates protect renal tissue against cisplatin-induced apoptosis via induction of heme oxygenase-1. Pharmacol Res. 2014;81:1-9.

73. Nakamura K, Tanaka Y, Mitsubuchi H, Endo F. Animal models of tyrosinemia. J Nutr. 2007;137(6):1556S-60.

74. Ruetschi U, Cerone R, Perez-Cerda C, Schiaffino MC, Standing S, Ugarte M, Holme E. Mutations in the 4-hydroxyphenylpyruvate dioxygenase gene (HPD) in patients with tyrosinemia type III. Hum Genet. 2000;106(6):654-62.

75. Kimura A, Ishida Y, Hayashi T, Wada T, Yokoyama H, Sugaya T, Mukaida N, Kondo T. Interferon-gamma plays protective roles in sodium arseniteinduced renal injury by up-regulating intrarenal multidrug resistanceassociated protein 1 expression. Am J Pathol. 2006;169(4):1118-28.

76. Kimura A, Ishida Y, Inagaki M, Nakamura Y, Sanke T, Mukaida N, Kondo T. Interferon-gamma is protective in cisplatin-induced renal injury by enhancing autophagic flux. Kidney Int. 2012;82(10):1093-104.

77. Pajor AM. Molecular properties of the SLC13 family of dicarboxylate and sulfate transporters. Pflugers Arch. 2006;451(5):597-605.

78. Burckhardt BC, Drinkuth B, Menzel C, Konig A, Steffgen J, Wright SH, Burckhardt $\mathrm{G}$. The renal $\mathrm{Na}(+)$-dependent dicarboxylate transporter, $\mathrm{NaDC}-3$, translocates dimethyl- and disulfhydryl-compounds and contributes to renal heavy metal detoxification. J Am Soc Nephrol. 2002;13(11):2628-38.

79. Cotta-Ramusino C, McDonald ER, Hurov K, Sowa ME, Harper JW, Elledge SJ. A DNA damage response screen identifies RHINO: a 9-1-1 and TopBP1 interacting protein required for ATR signaling. Science. 2011;332(6035):1313-7.

80. Thomas G, Betters JL, Lord CC, Brown AL, Marshall S, Ferguson D, et al. The serine hydrolase ABHD6 is a critical regulator of the metabolic syndrome. Cell Rep. 2013;5(2):508-20.

81. Fimognari C, Turrini E, Ferruzzi L, Lenzi M, Hrelia P. Natural isothiocyanates: genotoxic potential versus chemoprevention. Mutat Res. 2012;750(2):107-31.

82. Ponka P. Cell biology of heme. Am J Med Sci. 1999;318(4):241-56.

83. Skugor S, Glover KA, Nilsen F, Krasnov A. Local and systemic gene expression responses of Atlantic salmon (Salmo salar L.) to infection with the salmon louse (Lepeophtheirus salmonis). BMC Genomics. 2008:9:498.

84. Tadiso TM, Krasnov A, Skugor S, Afanasyev S, Hordvik I, Nilsen F. Gene expression analyses of immune responses in Atlantic salmon during early stages of infection by salmon louse (Lepeophtheirus salmonis) revealed bi-phasic responses coinciding with the copepod-chalimus transition. BMC Genomics. 2011;12:141.

85. Fast MD. Fish immune responses to parasitic copepod (namely sea lice) infection. Dev Comp Immunol. 2014;43:300-12.

86. Haugland M, Holst JC, Holm M, Hansen LP. Feeding of Atlantic salmon (Salmo salar L.) post-smolts in the Northeast Atlantic. ICES J Mar Sci. 2006; 63:1488-500. 
87. Krasnov A, Timmerhaus G, Afanasyev S, Jorgensen SM. Development and assessment of oligonucleotide microarrays for Atlantic salmon (Salmo salar L.). Comp Biochem Physiol Part D Genomics Proteomics. 2011;6(1):31-8.

88. Martinez-Rubio L, Morais S, Evensen $\varnothing$, Wadsworth S, Vecino JG, Ruohonen $\mathrm{K}$, et al. Effect of functional feeds on fatty acid and eicosanoid metabolism in liver and head kidney of Atlantic salmon (Salmo salar L.) with experimentally induced heart and skeletal muscle inflammation. Fish Shellfish Immunol. 2013;34(6):1533-45.

Submit your next manuscript to BioMed Central and we will help you at every step:

- We accept pre-submission inquiries

- Our selector tool helps you to find the most relevant journal

- We provide round the clock customer support

- Convenient online submission

- Thorough peer review

- Inclusion in PubMed and all major indexing services

- Maximum visibility for your research

Submit your manuscript at www.biomedcentral.com/submit 